\title{
Analysis of politeness strategies in Youtube reaction vlogs
}

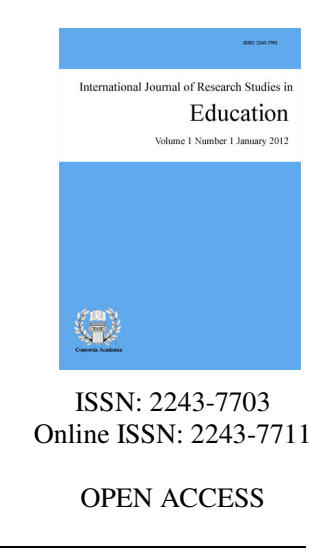

Alcosero, Irish Rose $\measuredangle$

Department of Education, Davao De Oro Division,Philippines (irish.alcosero@deped.gov.ph)

Gomez, Dan

University of Mindanao,Tagum, Philippines (dangomez031986@gmail.com)

Abstract

The purpose of this study was to analyze the politeness strategies used in YouTube reaction vlogs and how these influence viewers. Content analysis was employed in identifying the politeness strategies used in the vlogs using Brown and Levinson's politeness theory. The results showed that there were 231 polite utterances used. The frequently used politeness strategy was positive politeness (48.05\%), followed by bald on-record politeness $(25.11 \%)$, off-record politeness (13.85\%), and negative politeness (12.99\%). A phenomenological inquiry was employed to gain the insights of 14 educators as participants in in-depth interviews and focus group discussions on how politeness strategies in reaction vlogs influence viewers. The following themes emerged: make a good conversant, give respect and protect an image, train how to evaluate issues and reactions, learn to appreciate vlogs, and aid in the teaching-learning process. Reaction vlogs, as an investigative genre of vlogging, could become a springboard to teach politeness and politeness theory and supplementary materials in teaching. Reaction vlogging, as a form of self-expression, could serve as a performance task among learners.

Keywords: English, politeness, reaction vlogs, content analysis and phenomenology, Philippines 


\section{Analysis of politeness strategies in Youtube reaction vlogs}

\section{Introduction}

Social media is a term used to describe the interaction of people over the internet and in virtual communities. With the presence of social media platforms such as Facebook, Twitter, YouTube, and blogs, both positive and negative effects are evident in different fields like health, business, education, society, and youth. On the part of the professionals, the so-called online professionalism becomes a challenging task to maintain. Since they are professionals, people expect that they uphold politeness, etiquette, and professionalism not only in the workplace but also in social media. However, in many cases, especially in the medical arena, several posts and video content made by the medical practitioners showed unethical and unprofessional content that may damage the reputation of the entire profession. It is essential to realize the possible impact of social media content because everything posted can easily be accessed by the public (Greysen, Kind, \& Chretien, 2010).

Vlogging, also known as video blogging or video log, is a new form of computer-mediated communication and one of the most popular social media trends today. It is the act of recording videos of one's experiences, opinions, and thoughts and sharing them with the world through social media websites like YouTube (Frobenius, 2014). Its interactive, social, economic benefits and other impressive features attract not only Millennials and youth but also the professionals in the field of health, business, and education (Akram \& Kumar, 2017). Young and old, male and female, professionals and not, from different cultures and places, have watched vlogs and have created vlogs. In fact, as young as eight years old, a grade one student in Southville Elementary School here in the Philippines went viral for vlogging spontaneously using her teacher's phone. Some medical practitioners use vlogs to give health tips and some other professionals such as educators, businessmen, artists, and the like. Undeniably, YouTube vlogging has been an essential part of social media culture. However, Werner (2012) stressed that indulging in vlogging comes with great risk, not only to the profession that vloggers belong but in the sense that vloggers become vulnerable by the time they share their personal experiences and ideas online. Sharing thoughts in a digital world means opening doors for possible harsh criticism and distressing judgment from the audience. With this, Werner advocates immersive participation wherein vloggers must be able to learn first the convention of vlogging - contribute comments, discuss videos, and know its advantages and disadvantages to their personal lives - before creating their vlog. If not, they will either receive compliments or suffer criticisms from the viewers or audience.

Viewers and subscribers keep every vlogger going. Audiences' approving attitude could influence vloggers' video content as they will become flexible in creating content considering audience preferences to get active viewership. These audience preferences are directly found in the comment sections where one could commend, suggest, and even criticize vloggers' content (Chikwaya \& Zhang, 2018). Consequently, in the YouTube comment sections, several rude comments are created by users. For instance, in Asian country specifically in Malaysia, impoliteness strategies such as insult in the form of accusation and baseless claim, a show of superiority, mockery, and ridicule were evident in discussing a racial social issue (Xavierine \& Thayalan, 2017). This result is a manifestation of how people become so quickly vulnerable in social media. The sudden burst of emotion and access to freedom of easily writing and posting opinions publicly could cause chaos that may divide one nation rather than promote a solidarity that embodies unity and peace. Thus, it is imperative to examine vlog's content before uploading to achieve a harmonious relationship between vloggers and viewers.

Moreover, in the study "Impoliteness in Criticism in Vlog," males tend to be more impolite than females in responding to vlogs. Males tend to use positive impoliteness strategies through using taboo words and name-calling, whereas females use negative impoliteness strategies such as condescending, scorning, and ridiculing (Rosanti, Wijayanto, \& Hikmat, 2017). Since there are several genres of vlogs ranging from tutorials, rants, reactions, confession, and witness vlogs, as a researcher, I choose to delve more into reaction vlogs. As 
vloggers, who are also professionals in their field, express their opinions and views on a particular topic, they tend to be polite or impolite. This aspect now puts the study of politeness strategies in place. In the reaction vlogs created by professionals, there could be manifestations of acts of politeness and even impoliteness. With this, I decided to explore more on this research topic.

Many researchers have studied politeness in the field of pragmatics. I came across a study of politeness strategies in Facebook announcements here at Tagum City. In addition, Johansson (2017) pointed out that studies about politeness were more focused on the analysis of written forms and text-based interactions. These include the studies on WhatsApp communication (Mulyono, Rizki, \& Suryoputro, 2019), Twitter updates (Maros \& Rosli, 2017), class blog (Adel, Davoudi, \& Ramezanzadeh, 2016), and text messaging (Eshghinejad \& Moini, 2016). However, there are still fewer attempts to study politeness strategies in the context of spoken media. Some examples include classroom communication (Jiang, 2010), movies (Mulyono, 2016), political speech (Sari, 2016), and courtroom discourse (Liao, 2019), but none have studied yet politeness strategies in the context of reaction vlogs. To address these gaps, I decided to delve more into the study of politeness strategies in the context of reaction vlogs and how the politeness strategies used influence viewers.

\subsection{Purpose of the Study}

The purpose of this phenomenological study was to examine the politeness strategies used by YouTube vloggers in reaction vlogs and understand how these strategies influence viewers. The politeness strategies used in the vlogs were identified and analyzed by the researcher and English language teachers. Then, these data were collected through the conduct of in-depth interviews and focus group discussions. YouTube is a social networking site that has millions and billions of users. With the pandemic, some of the people worldwide had been spending most of their time online browsing social media and binge-watching YouTube videos. With this, their lifestyle and personality may be influenced by doing such. Thus, one of the purposes of this study was to examine the personal experiences of the viewers/audiences of YouTube vlogs.

Secondly, in connection to the theoretical background underlying this research, I presumed that politeness strategies could manifest more in reaction vlogs compare to its other genres such as tutorials, rants, confession, witness vlogs, and other forms. In giving responses, vloggers may employ any of the four politeness strategies from Brown and Levinson's taxonomy. Moreover, with the literature reviews saying that the study of politeness strategies was most popular in text-based media and rare in spoken form, this study may help expand the existing investigation of this field. Thus, this research aimed to contribute to the growing body of literature in the field of pragmatics.

Lastly, this research aimed to know how the knowledge about politeness strategies in vlogs influenced the research participants who are English language teachers. With both the research participants and vloggers professionals in their respective fields, this research sought to yield an exciting result that could benefit both parties. More so, as this study intended to understand the convention of vlogs concerning politeness and how these influence viewers, the researcher aspired that the results and conclusions obtained would encourage language teachers to use vlogs for academic purposes.

\subsection{Research Questions - This study delved into answering the following questions.}

$>$ What are the politeness strategies used in YouTube reaction vlogs?

$>$ How do these politeness strategies in YouTube reaction vlogs influence viewers?

\subsection{Theoretical Lens}

Penelope Brown and Stephen Levinson developed the first theory of Linguistic Politeness in 1978 called the Face-Saving Theory of Politeness in their work "Universals in Language Usage: Politeness Phenomena." 
According to Brown and Levinson, a speaker uses politeness strategies to save the hearer's "face." Face refers to the positive self-image or self-esteem a person enjoys based on other's estimation of him. An individual's "face" consists of two desires: the desire to be approved by others, thus making their wants to be considered desirable (positive face goal) and the desire to be unimpeded by others in one's actions, that is the desire for freedom in action and freedom from imposition (negative face goal). Either or both are threatened by certain FTAs, such as negatively expressing thoughts to the hearer or acting as the speaker do not care about the hearer's face. Face Threatening Acts (FTAs) are acts that infringe on the hearer's needs to maintain their self-esteem and to be respected. As such, politeness strategies' main purpose is to deal with these FTAs. They are called positive Politeness, negative Politeness, bald on-record, off-record Politeness, and do not do FTAs. Among these strategies, the first four are given more emphasis by the proponents than the fifth. With this, the first four politeness strategies are the basis of analysis in this study.

Accordingly, the use of positive Politeness helps show solidarity between hearer and speaker through giving some positive value to the addressee, such as thanks, apologies, and congratulations. Negative Politeness, also known as respect politeness, uses a very formal way of mitigating face-threatening acts (FTA) through ensuring lesser possible causes of offense that would occur if one expresses words in their bluntest form. On the other hand, bald on-record Politeness refers to direct utterances used by the speaker using clear statements to avoid misinterpretation in the hearer, and off-record Politeness refers to indirect words used to take some pressure off the hearer using vague manners leading to more than one meaning to the hearer (Leech, 2014).

Concerning the study at hand, YouTube vloggers may appear to save or threaten the hearer's face when giving their reactions to particular topics through applying positive and negative politeness strategies. On the other hand, YouTube vloggers may perform Face Threatening Acts (FTA) directly and clearly through employing bald on-record or indirectly and ambiguously through off-record politeness strategies. To support Brown and Levinson's theory, Geoffrey Leech suggests that one has to maximize the expression of polite beliefs and minimize the expression of impolite ideas. His model formulated the six politeness maxims that include tact, generosity, approbation, modesty, agreement, and sympathy maxims. He calls them the general conditions of the communicative use of language. Accordingly, a speaker is polite if he is tactful, generous, and modest towards the hearer; and when he gives praise, sympathy, and agrees with the hearer. Leech's maxims focused on politeness as strategic conflict avoidance centered on the attempt of avoiding a situation where conflict may arise (Leech, 1983; 1980).

In connection to politeness theories, J.L. Austin's (1965) Speech Act Theory states that we perform speech acts every day like greeting, apologizing, requesting, and complaining, and so on. Thus, by saying something, we either act (performatives) or just state things (constative). Speech acts are classified as utterances/words (locution), intention/meaning (illocution), and effect on the hearer (perlocution). Speech Act Theory explains the use of language concerning the context, the attitude of the speaker, and its effect on the hearer. As such, when vloggers say something, no matter the words they used and the intention they have, have an impact on the hearers. Same to say, whether their utterances are polite or not, it could either save the hearer's "face" or tolerate Face Threatening Acts (FTAs). With these underlying theories, I opt to examine the politeness strategies used by YouTube vloggers through the lens of Brown and Levinson's Face-Saving Theory of Politeness. Thus, this research aimed to understand how YouTube vloggers used positive and negative politeness, or bald on-record and off-record politeness.

\subsection{Significance of the Study}

With the domination of YouTube vlogs in social media, there are various researches conducted to explore its convention and potential benefits to the community. Upon the completion of this study, it will be beneficial to the following: Firstly, to the linguists, this study could contribute to the field of pragmatics and linguistics as this investigates not written internet platforms such as chats, posts, and tweets which are the products of most researchers today. This study delves into speech corpora that examines the authentic utterances of several people 
in various speech contexts.

Secondly, this study could help educators to devise another way to teach speaking skills to the students through using vlogs as additional classroom instructional materials. Educators may integrate vlogs in the classroom by showing them and letting students examine their conventions and learn from them. Further, some learners nowadays are visually inclined, so videos could motivate them and tickle their class interests. Thirdly, this study may make learners realize that vlogging is not only a form of entertainment but something educational. They may use vlogs to improve their communication skills, not limited to spelling and speaking skills. In doing so, I hope they become media literate and responsible internet users. Lastly, this study may serve as an inspiration to vloggers to continue using politeness strategies in their reaction vlogs. As they become aware of these strategies, they may gain more supporters or subscribers to the platform.

\section{Review of Related Literature}

\subsection{Politeness}

Pragmatics is the study of linguistic acts and their contexts. It is the study of meaning as communicated by a speaker and interpreted by a listener. It encompasses the speaker's social competence in knowing what to say, how to say, and when to say a particular talk in a specific social context. Also, pragmatics covers broad theories and principles like speech act theory, theory of conversational implicatures, cooperative principle, politeness principle, and irony principle. Thus, in this research, the researcher focused on the politeness principle governing the study of pragmatics (Stalnaker, 1972). Politeness, as generally viewed by people as an expression of moral conduct, sparked a debate since the 1970s about how it is linguistically and socially measured. Accordingly, there are at least three social factors that influence one's decision to be polite. First, one tends to be more courteous to their superiors; second, one is more polite to people one does not know; and third, being polite depends on one's culture of acceptable polite norms. Either way, it is essential to note that polite utterances are dependent not just on the language that one used but also on the social characteristics of the interlocutors (hearer and speaker) and the situation they are in (Brown, 2015).

Moreover, there are different notions of politeness when emphasizing the facet of social-norm view, conversational maxim, and concept of "face." From the social-norm perspective, politeness and impoliteness are classified when one is conforming or non-conforming to the acceptable norms of society. On the other hand, the conversational maxim, as proposed by Grice, viewed good conversationalists as rational individuals capable of conveying messages efficiently. Finally, Brown and Levinson's taxonomy viewed politeness as the effort of a conversationalist to satisfy the hearer's positive and negative face (Fraser,1990).

Historically, Brown and Levinson developed the first theory of Linguistic Politeness in 1978 in their work "Universals in Language Usage: Politeness Phenomena." Although there are many criticisms on some parts of their work, this theory has been the most preferred theory regarding politeness. According to Brown and Levinson (1987), politeness strategies helped to save the hearers' "face." Face refers to the public image of both the hearer and the speaker. It consists of the desire to be approved by others (positive face) and the desire to be unimpeded by others in one's action (negative face). This "face" could be threatened by Face Threatening Acts (FTAs) such as ordering, advising, or offering but saved by Face Saving Acts (FSAs) like praising, well-wishing, blessing, complimenting, etc. As such, with the notion of face, dealing with these FTAs is the primary purpose of the politeness strategies. They are called positive Politeness, negative Politeness, bald on-record, and off-record Politeness.

Parallel to Brown and Levinson's politeness strategies is the impoliteness super strategies based on the taxonomy of Jonathan Culpeper. These super strategies include bald-on record impoliteness, positive impoliteness, negative impoliteness, off-record impoliteness, withhold impoliteness, and the meta-strategy mock politeness. Unlike politeness strategies, Culpeper's model focused on impositions in circumstances where the 
face is not conserved. These are manifested in FTAs like ignoring, snubbing, frightening, mocking, and the like that tend to damage an individual's face. With this standpoint, Culpeper's model of impoliteness also provides a relevant perspective on how to consider someone polite or impolite (Culpeper,1996).

In connection to this, since politeness is manifested in people's utterances, it is important to understand its meaning and consequences. For instance, when a speaker performs speech acts such as making statements, asking questions, or giving commands, his utterances are geared with intention and function that may affect the hearer. Thus, what the utterances mean, what the speaker intends, what the hearer understands, and what the rules governing linguistic elements are, are carefully examined since these aspects are essential in understanding the full meaning of utterances and their consequences (Poluzhyn \& Vrabel, 2005).

Austin's Speech Act Theory (1965) developed by Searle (1975), defined the speech act as an utterance that serves a function in communication. He emphasized the pragmatic phenomena arising in speech - that speech may accomplish an action realized in the actual words uttered (locution), the force or intention behind the words (illocution), and the effect of the illocution on the hearer (perlocution). Therefore, the hearer plays an important role in the process because if the hearer fails to understand what the speaker is trying to say, the illocutionary act failed to fulfill its purpose (infelicitous or inappropriate). Thus, according to the speech act, an action is performed using language. Human beings have a wide choice of linguistic expressions to make things happen. However, it is essential to note that certain speech acts are performed depending on social context. Thus, the interpretation of speech acts differs throughout the cultures, and the illocutionary act performed by the speaker can be easily misinterpreted by a member having a different cultural background. In connection to the study at hand, what acts others hold polite may be considered impolite to others and vice versa. This thought further intensifies the notion that the politeness taxonomy of Brown and Levinson could not be universal, since it could vary depending on cultural background (Al-Duleimi, Rashid, \& Abdullah, 2016).

\subsection{Positive Politeness}

First, positive politeness strategies help reduce the threat to the hearer's positive face (Brown \& Levinson, 1987). A positive face refers to the wants to be approved by others. Specifically, this strategy fits in maintaining the hearer's positive face through expressing approval, care, and social closeness to establish solidarity and harmonious relationship. When the level of threat incurred by the FTA is low, this strategy is appropriate (Brown, 2015). The following positive politeness sub-strategies are (i) acknowledging the hearer's interest, wants, and needs; (ii) exaggerating; (iii) deepening the interest to the hearer; (iv) use of in-group identity marker; (v) finding agreement; (vi) avoidance of disagreement; (vii) assertion of common ground; (viii) joking; (ix) assertion of speaker's knowledge of and concern for the hearer's face; (x) offering or promising; (xi) being optimistic; (xii) participation of the speaker and hearer in an activity; (xiii) giving or asking for reasons; (xiv) assuming or asserting reciprocity; and (xv) giving rewards to the hearer (Brown \& Levinson, 1987).

In using positive politeness, the speaker's intention is generally to build friendship and familiarity. In this way, the conversation between the interlocutors depicts a relaxed and friendly atmosphere. The sub-strategies such as offering, using group identity markers like slang, avoiding disagreement, exaggerating, and requesting have helped establish the harmonious relationship of the main characters of the movie Tinker Bell in Secret of the Wings (Mujiono \& Ula, 2020). The use of an in-group identity marker helped build a harmonious relationship between teachers and learners in the class. This positive politeness strategy pertains to the speaker including himself in the conversation, such as using the pronouns "we" and "us" instead of using "you." In this way, positive politeness maintained the positive face of the learners and satisfied their desire to be liked and approved of, judging from the teacher's involvement in the same experience. As a result, they would feel closer to their teacher, thus shortening the social distance in the class (Jiang, 2010).

In connection to this, in the study of politeness strategies in the oral discourse between male and female EFL teachers with their students in Iran, the use of positive politeness strategies was evident to maintain the positive 
face of the students and protect their self-image. These are manifested by teachers when offering help and showing sympathy and understanding to students' situations. Therefore, the use of more politeness strategies directly affects the learning process and teacher-student interaction (Monsefi \& Hadidi, 2015). Moreover, giving compliments and praise is one of the positive politeness strategies used to maintain the hearer's face. It fosters emotional function in the language used to convey feelings and reflect the social relationship. People use compliments to give credit and positive value to someone's appearance, ability, possessions, personality, and other characteristics. It is essential in establishing rapport, common ground, and solidarity between speaker and hearer (Al-Azzawi, 2011).

On the one hand, positive politeness aids in solving the emerging conflicts between people. In fact, in the council meetings in Iran where the participants were husband, wife, and judge, the sub-strategies such as noticing and attending to the hearer, seeking agreement, and avoiding disagreement were used. Accordingly, since the goal of the conversation was to solve a dispute between two parties, the participants have established common ground. In this way, they tended and listened to each other's utterances to arrive at a consensus (Dowlatabadi, Mehri, \& Tajabadi, 2014). Another way to use positive politeness is convincing customers to buy products through advertising. Compared to Persian culture, English advertisers have used positive politeness strategies such as showing concern, offering, promising, complimenting, joking, and exaggerating to convince customers. In these ways, the advertisers shortened the social distance by making the customers feel closer and connected to them (Pishghadam \& Navari, 2012). Furthermore, in two episodes of the talk show Ellen DeGeneres where Barack Obama was the guest, the use of positive politeness strategies was evident. Although the host had all the opportunity, power, and domination to threaten the guest's face because it is her territory, she had uttered statements and strategically asked questions that would save the guest's face who is much more powerful than her. She did it by agreeing with the guest and attending to his wants and interests (Dharmayanti, Sukarini, \& Savitri, 2018).

\subsection{Negative Politeness}

Second, negative politeness, also known as respect politeness, indicates that the speaker respects the hearer's freedom of action and freedom from the imposition or the negative face goal (Brown and Levinson, 1987). Thus, the speaker maintains the hearer's negative face through manifesting self-effacement, formality, restraint, and maintaining the hearer's self-image. In doing such, the speaker redressed the imposition in a much greater effort to save the hearer's negative face. With this, there is a higher level of threat caused by an FTA than positive politeness; thus, negative politeness is more used (Brown, 2015). From Brown and Levinson's theory (1987), ten strategies are classified under negative politeness. These include (i) being conventionally indirect, (ii) questioning or hedging, (iii) being pessimistic, (iv) minimizing the imposition, (v) giving deference, (vi) apologizing, (vii) impersonalizing the speaker and the hearer, (viii) stating the face-threatening act as a general rule, (ix) nominalizing, and (x) to go on-record as bringing down debt or not recognizing the hearer.

In the casual conversation among graduate program students in Indonesia, the use of eight sub-strategies of negative politeness, not including giving deference and nominalizing, was observed. Although the interlocutors already established friendship and closeness with one another, their varying cultures influenced their utterances. Specifically, when they performed the FTAs, such as requesting, confirming, commanding, and giving and asking information, the interlocutors ensured to save their negative faces. Thus, they became cautious with their utterances not to offend one another and to establish mutual respect (Sulistiyaningsih, Mujiyanto, \& Widhiyanto, 2021). Moreover, in Indonesia, when the students used politeness strategies in communicating with their lecturers, the negative politeness strategies they used lessened the displeasure of the lecturer to their requests. For instance, the students used a pessimism strategy in the line "It seems like I can't get the exam on August, Sir!" hoping that the lecturer would take the pressure off from them. More so, the students were conventionally indirect when they said, "Do you have free time today, Sir?" instead of "May I consult today?" to reduce the possibility of the lecturer's unwillingness to act. In these ways, the impact of the imposition lessened because the speakers exercised restraint and formality in the conversation (Rohali, 2019). 
In addition, negative politeness strategies helped in attaining the teacher's goals of presenting the lesson, answering students' questions, and giving feedback. Negative politeness gives the students freedom to act as they choose in class. For instance, the teacher impersonalized the hearers by not mentioning their names to maintain their negative faces. Thus, the teacher sustains the atmosphere of respect by protecting the students' image as well as protecting her image (Jiang, 2010). In media and television, when Ellen DeGeneres, a famous host, interviewed Barack Obama, the former US president, negative politeness is used. The host minimized imposition in the interview by using words that would not insult the guest; thus, paying respect to the person with high authority. In return, the guest also responded to the questions without offending the host. Therefore, both interlocutors had protected each other's image by not being rude and too imposing with their utterances (Dharmayanti, Sukarini, \& Savitri, 2018).

In the Oprah Winfrey Show with Ricky Martin as the guest, being conventionally indirect, hedging, being pessimistic, and apologizing were the negative politeness sub-strategies used. First, in being conventionally indirect sub-strategy, the guest successfully becomes indirect at the same gone on-record. Second, hedging or questioning allowed the guest to avoid being too imposing on the host's view. Third, being pessimistic helped the guest expressed doubt about the situation but seemed amazed and awed at the same time. Lastly, apologizing granted allowance to the speakers to admit reluctance of utterance. Hence, these negative politeness sub-strategies kept the distance between the two interlocutors as the guest exercised formality and restraint in expressing his views (Putri, 2013).

\subsection{Bald on-Record Politeness}

Next, bald on-record politeness strategies pertain to the speaker's use of direct utterances to express his needs to the hearer (Brown and Levinson, 1987). In this strategy, the goal of satisfying the hearer's needs is not the utmost priority but the imposition and its message. Furthermore, bald on-record politeness is applicable when the threat to the hearer's face is minimal or in a situation when the speaker is more potent than the hearer (e.g., between parent and child) (Culpeper, 1996). Thus, just like positive politeness, bald on-record politeness is mainly used when the level of threat brought by FTA is low (Brown, 2015).

In the following situations, the bald on-record politeness is used: (i) maximum efficiency (being urgent and desperate), (ii) metaphorical urgency for emphasis, (iii) metaphorical urgency for high valuation of hearer's friendship, (iv) case of channel noise, (v) task-oriented way of instruction, (vi) power difference between speaker and hearer, (vii) sympathetic advice or warnings, and (viii) permission from hearer's request. Further, the following is the list of payoffs associated with this strategy. By using bald on-record, a speaker can (a) enlist public pressure against the hearer or in support of himself, (b) get credit for honesty and for indicating trust to the addressee, (c) get credit for outspokenness, and (d) avoid the danger of being misunderstood and seen as manipulator (Brown \& Levinson, 1987).

Bald on-record politeness is used to state an utterance as it is. It means that there is no covering of its true meaning, usually observed when someone is in a state of emergency. In fact, in the study of the utterances between students and lecturers in Indonesia, bald on-record politeness helped warn the lecturer directly of something terrible that would happen. Through giving warning, the hearer was notified immediately on what to do (Rohali, 2019). Similarly, on the finding generated from the analysis of the Beauty and the Beast movie script, bald on-record politeness was used when the speakers or listeners were in a rush. This urgent circumstance leads someone to state his intention in a clear statement without further ado. As such, the listener unambiguously grasped the goal of the utterance because the possibilities of misinterpretation were prevented beforehand through indirectness (Febtrina, 2019).

In addition, bald-on record politeness is used to emphasize the importance of something. With this, the speaker would speak as if maximum efficiency were required to convey a particular point of contention. In these situations, there are fewer redressive utterances employed by the speaker because the urgency and relevance of 
the information were put first (Putri, 2013).

In a case study of teacher's politeness in EFL class in China, the teacher used bald on-record politeness in most of the classroom management. The teacher used direct speech through giving task-oriented instructions like "Be quiet, please!" and "Stop talking, please!" as ways to maintain discipline in the shortest time possible. As the teacher holds power to give these orders in the class, the students were obliged to follow. Thus, the message of the utterance is immediately realized (Jiang, 2010). Similarly, in the oral discourse between Iranian teachers and students, bald on-record politeness is applied by teachers in giving commands, instructions, and requests. In these scenarios, the teachers were not trying to minimize the threat of the FTAs to the students' faces. Instead, they expressed the need to do the imposition and created pressure to do what is asked (Monsefi \& Hadidi, 2015).

Generally, in class, a teacher used bald on-record politeness to give clear instructions and direction on what to do. However, in ordinary conversation, she gives suggestions and advice on the right or wrong thing to do. Consequently, students responded by agreeing or disagreeing with the teacher's idea. To address this, the teacher gave task-oriented instruction and warnings to express her intention of presenting effective options to do. This teacher-students exchange of bald on-record politeness depicts that no redressive acts were applied by the interlocutors. Therefore, the potential damage it could cause to each face is low (Rahayuningsih, Saleh, \& Fitriati, 2020).

\subsection{Off-Record Politeness}

Lastly, off-record politeness strategies involved using indirect language to remove the speaker from the potential to be imposing (Brown and Levinson, 1987). In this strategy, the speaker remains vague and ambiguous with his utterance and lets the hearer formulates an interpretation. In this way, the speaker will not be held responsible for what the hearer may think and act. One resorts to using off-record because the potential threat of the imposition to the hearer's face is very high, and being indirect/off-record is the safest option (Brown, 2015). 15 strategies are indicating off-record politeness, according to Brown and Levinson (1987). These are (i) giving hints, (ii) giving association clues, (iii) presupposing, (iv) understating, (v) overstating, (vi) using tautologies, (vii) using contradictions, (viii) being ironic, (ix) using metaphors, (x) using rhetorical questions, (xi) being ambiguous, (xii) being vague, (xiii) overgeneralizing, (xiv) displacing the hearer, and (xv) being incomplete by using ellipsis. Accordingly, by employing off-record politeness, the speaker can satisfy negative face to a degree more significant than what negative politeness strategy can afford, and the speaker can avoid the inescapable accountability and responsibility manifested in bald on-record strategy.

In constructing off-record utterances, one is also inviting the use of conversational implicature. It means to say that the speaker is implying something more than what the utterance means. Sometimes, one uses indirect utterances to give additional information or to say something different from what one means. In the study of off-record politeness in Oprah Winfrey Show, there were 14 off-record sub-strategies used by the host and guests, excluding the use of metaphors. Consequently, the use of off-record politeness depends on the context of the situation, assertion, and intonation. Nonetheless, someone is more polite when the language being used is more indirect (Yanti, 2017). Similarly, in the same talk show with Ricky Martin as a guest, the off-record sub-strategy used was the giving of association clues. It happened when the guest talked about child trafficking. Instead of directly saying, "We should dissolve this institution," the guest expressed his wants by asking the audience questions about the consequences when the said institution did not exist. In this way, the guest indirectly told people that they should do something without giving concrete and detailed instructions on what to do. As a result, the audience, including the host, were left to infer the possible actions to do to solve the social issue. Reciprocally, the guest was in a safe position on possible criticism incurred in his utterances for being neutral and indirect (Putri, 2013).

In connection to this, although off-record is the least used politeness strategy in the teacher-student interaction, it is considered the politest strategy because it allows the speaker to avoid the responsibility of 
potentially face-damaging interpretations. This avoidance of damage was achieved by the teacher and students through using the sub-strategy giving hints. Based on the result, when the teacher did not want to assess students' output individually, she said, "I am standing here" which indirectly sent a message that she wanted them to write their answers on the board. In return, the students commented on a piece of certain broken equipment to hint that they did not wish to proceed to the activity. As a result, there was a smooth exchange of off-record politeness by the interlocutors because of the asymmetrical power relationship between the teacher and students in the class. Thus, power and social closeness are essential factors in using off-record politeness (Rahayuningsih, Saleh, \& Fitriati, 2020).

Another excellent example of speech acts that attempt to make the audience do something is advertising. It is the goal of an advertisement to persuade the audience to buy certain products. Unlike American culture, Persian advertisers have used off-record sub-strategies such as giving hints, contradictions and being vague. Their usage implies that Persian advertisers showed unwillingness in making imposition to the customers by leaving the decision and interpretation to them. In such a way, the customers have the upper hand in the decision process, and the advertisers have no direct responsibility for their actions (Pishghadam \& Navari, 2012). Moreover, being ambiguous is another off-record sub-strategy. In every communication process, verbal cues are not the only aspect that listeners or viewers notice but also the non-verbal cues. Sometimes, people tend to have different interpretations of a single utterance, because they do not only listen to every word but also watch the facial expressions. Inherently, facial expressions of people's emotions are ambiguous. As a result, it is hard to read them correctly and even universally. With this, it is imperative to consider the role of context to interpret facial expressions of emotions more appropriately (Hassin, Aviezer, \& Bentin, 2013).

In connection to the ambiguity of non-verbal cues, another off-record sub-strategy a speaker could employ is irony. Although many linguistic researchers debated about the difference between irony and sarcasm or whether they could use them interchangeably, the notion of face-threatening and face-saving acts helped to explain them. Accordingly, the irony could be described as face-saving criticism, while sarcasm could be both. For instance, the hearers could ignore sarcasm while speakers compromise themselves for the sarcastic utterance. Hence, when using sarcasm, the hearers' faces could be saved but not the speakers' (Barbe, 1995, as cited by Prokofiev, 2017). Primarily, one could detect irony and sarcasm through its commonly used prosodic features and non-verbal signals. The prosodic markers of irony and sarcasm are highness and lowness of pitch, singsong melody, heavy exaggerated and broad stress patterns, monotonous intonation, long pauses between words, syllable lengthening, laughter syllables, and the like. On the other hand, facial markers include raised or lowered eyebrows, wide open or rolling eyes, winking, nodding, smiling, blank face of the speaker, and many others (Gibbs, 2000, as cited by Prokofiev, 2017).

\subsection{Aftereffects of Using Politeness Strategies}

Being able to sustain a conversation is very important in achieving successful communication. Being able to do so requires exposure, practice, and careful use of politeness strategies. In fact, in the study of positive politeness address terms in the classroom setting at Timor University, most of the students were able to perform the acts such as greeting, thanking, apologizing, praising, questioning, requesting, disagreeing, suggesting, and rejecting. Although the findings of this research showed that students were able to use positive politeness strategies, they still need more exposure and practice to further develop their skills on the least employed address terms. In doing such, they would be able to maintain the conversation and achieve a harmonious relationship with other people (Kamlasi, 2017).

In fact, in the analysis of President Joko Widodo's interactions in his vlog session with Indonesian citizens, the president has been very successful in controlling and managing his reactions. For instance, when viewers asked questions and gave opinions, President Widodo politely answered and advised by using positive politeness strategies. He exercised caution in sharing his thoughts to establish a harmonious and comfortable atmosphere of communication. At the same time, he used tag questions like "Yes, right?" to increase people's interest and 
Analysis of politeness strategies in Youtube reaction vlogs

interaction with him. This bravery of using vlogs to communicate with numerous people in a political world and is equipped with the knowledge of politeness principles could surely make one an effective and polite speaker (Susanti \& Rohmadi, 2018).

On the one hand, when sensitive and controversial topics are at hand, Brown, and Levinson (1987) emphasized applying a more elaborate politeness strategy. In the following instances, when the topic can potentially offend or embarrass hearers, or when pointing out bad choices of people, or when one is torn between telling the truth on things that one should be quiet about, one cannot afford to comment bluntly but must be polite. Therefore, as the degree of a possible threat of an imposition increases, one should strategically use politeness strategies. However, when the goal to be polite is prioritized, there were tendencies that the clarity of information is sacrificed. Thus, the more politeness is applied, the more risk of misunderstanding would occur, especially in high stake situations like medical emergencies and life-and-death situations. Accordingly, whenever a case crosses the politeness threshold, confusion arises because statements are made less clear because of wanting to avoid offense on hearers. With this emerging conflict, two options could be employed to minimize confusion: first, encourage people to be less polite in high-stakes situations, or second, make polite statements easier to interpret (Bonnefon, Feeney, \& De Neys, 2011).

In connection to this, as explained in conversational constraints theory, people from different cultures say what they say because of five motives. These include concern for avoiding hurting hearer's feelings, concern for minimizing imposition, concern for avoiding negative evaluation by the hearer, concern for clarity, and concern for effectiveness. Given these factors, whichever one chooses to put first, affects the conversational strategies and tactics employed (Kim, 2017). For example, in the study of politeness strategies in Barack Obama's victory speech in the 2008 elections, the use of both positive and negative politeness strategies was evident in gaining support and trust and establishing a relationship with people. Positive politeness strategies used include joking, exaggerating, giving sympathy, and cooperating to get the audience's interest. On the other hand, negative politeness helped in showing respect and submission. This mixture of strategies employed depicts the speaker's consciousness of the function of communication. With that knowledge, he was able to differ his politeness that suits the purpose of the context of communication (Sari, 2016).

On the other hand, in the analysis of politeness strategies in Prime Minister Tony Abbot's speech about the Australia-Indonesia tapping issue, unlike President Obama, Abbot performed FTAs that threatened the positive and negative face of the hearers as well as his positive face. These include teasing at the same time convincing people that he cared for them. It was the influence of the urgency and seriousness of the issue at hand that allows him to choose varying strategies. As a result, through his selection of strategies, he expressed his desire to be listened to, to be heard, to be trusted, and to be agreed upon by the hearers (Handoko, 2014). The context of communication influenced the two leaders in their usage of both positive and negative politeness strategies. Although both contexts were political, the nature of social issues or topics varied. The notion of context in the study of interactional competence and pragmatics does not only pertain to the time and place of utterance. Context also includes the physical, spatial, temporal, social, interactional, institutional, political, and historical circumstances in which a statement is spoken or heard (Young, 2019).

In addition, the use of positive and negative politeness in communication depicts the increasing degree of politeness in the utterance. To differentiate, in negative politeness, to increase politeness, we diminish the expression of negative value in the imposition. In contrast, in positive politeness, we magnify or strengthen the expression of positive value. With this, increasing politeness is associated with wordiness. For instance, instead of saying, "Lend me your pen," politeness would transform the sentence into "Could you lend me your pen?" or "I wonder whether you would be kind enough as to lend me your pen." (Leech, 2014, p. 12). Extending its scope and practicability even further, in the study of the pragmatic role of politeness in the interaction between employers with some clients in government offices, instances of speech interruption, keeping client waiting, and ambiguous talking were evident as examples of FTAs. Although there were instances of paying enough attention to the client's discourse, it is still alarming to note that seeing such behavior in an institutional interaction could 
threaten the client's expectation to be treated well. Given this circumstance, the staff must be equipped with pragmatic competence to implement politeness strategies necessary in their context to save the clients' faces and to maintain solidarity and friendship (Hedayat \& Kazemi, 2018).

Although being polite may be hard for almost all people, it is nothing compared to the Japanese people. As being polite is considered part of the Japanese culture, there was a study conducted about the so-called backchanneling behavior. Backchanneling behavior refers to the verbal and non-verbal responses or reactions of a listener when a speaker speaks. British people thought that the more Japanese interlocutors used backchannels, the more they feel they are interrupted. However, to the Japanese speaker, they used backchannels to give sympathy and support to the speaker. Therefore, Japanese people are aware and sensitive about the interlocutor's negative face, although it still depends on their social status (Cutrone, 2011).

On the contrary, since most of the studies of politeness primarily focused on ordinary and everyday communication, an attempt to study politeness in an institutional setting paved the way to the study of courtroom discourse. The findings showed statements indicating negative politeness, positive politeness, and negative impoliteness by judges, lawyers, and prosecutors. However, none of the models of politeness (Leech and Brown \& Levinson) and even impoliteness (Culpeper and Bousfield) could fit the study of politeness phenomenon in the courtroom discourse. Although the models are not completely outdated, politeness in courtroom discourse should be studied not only for being polite and for the sake of studying linguistic phenomenon but extending the study of politeness on the issue of ensuring social justice and protecting human rights. Therefore, a much thorough study of the politeness principle in courtroom discourse is needed to explore more the nature of politeness and its impoliteness (Liao, 2019). More so, a study on electoral debates comparing it to casual conversation proved to be much harder to disconnect each one from another. Since the communicative goal of electoral disputes is to win the argument, there is a presence of politeness and impoliteness. Thus, just like courtroom discourse, studying politeness strategies in electoral disputes could help explain the politeness principle in the type of communicative situation where politeness and impoliteness seemed natural and ordinary (Garcia, 2014).

\subsection{Understanding the Popularity of Vlogs}

YouTube was founded in February 2005 by Chad Hurley and Steve Chen. Then, Google acquired YouTube in 2006 and finally became very popular worldwide. It is a social networking site wherein users could stream, download, and upload songs, videos, documentaries, formal talks, vlogs, and other content. In addition, it is also very accessible through personal computers and mobile phones. The secret in attaining a successful YouTube channel lies in vlogger's natural ease on the camera, transparency, social interaction, personal branding, and shared experiences and interests with the audience (Rea, 2015). As long as people are interested in watching other people, video blogs will always be popular. However, the video content preferences of the audience are constantly changing. Thus, there is no guarantee that vloggers could maintain their popularity throughout (Mironova, 2016).

Theoretically speaking, the Uses and Gratifications Theory developed by Katz and Blumler in 1974 states that media users play an active role in choosing and using media. Users take an active part in the communication process, and they are goal-oriented in their media use. Therefore, people use media differently considering the benefits it could bring to their lives. In general, people use mobile phones for different uses and gratifications. These include affection/sociability, entertainment, instrumentality, fashion/status, mobility/immediate access, and psychological reassurance (Leung \& Wei, 2000). That is why there are different kinds of vlogs generated and closely watched by media users, such as travel vlogs, beauty tutorials, music tutorials, dance tutorials, rants, witness vlogs, and the like depicting people's lifestyles, experiences, and media content preferences.

Specifically, in the field of advertisement, vlogs are something that helps many business establishments and brands reach wider audiences. When there is trust built between vloggers and followers, the audience could 
Analysis of politeness strategies in Youtube reaction vlogs

easily change the product they are using based on the YouTuber's recommendation. Thus, vloggers do not only become famous, but they are now part of brand promotion or branding strategies (Khalid \& Siddiqui, 2019). Hence, vlogging is not just a form of entertainment but a platform where commerce could benefit impressively. Moreover, education could also benefit from vlogs, especially on the speaking skills and motivation of the learners (Valimbo \& Hartati, 2019; Warmbrodt, 2007). Speaking is a macro-skill that is harder to teach nowadays because of public speaking anxiety or fear in public speaking or stage fright. Fear is manifested before or during speech presentations because learners are afraid to commit mistakes, especially on grammar and pronunciation, lack vocabulary knowledge, and lack practice (Coskun, 2016; Sadighi \& Dastpak, 2017). With this, some researchers found that vlogs could help learners improve their speaking skills.

In public speaking, learners establish connections and rapport with the audience. Similarly, YouTube vloggers usually employ opening and closing strategies similar to face-to-face communication (De Boeck, 2015). Moreover, learning to speak their minds publicly is a valuable skill learner could get in creating vlogs. Voicing out their opinions on critical social issues like bullying is one of the manifestations that vlogging could indulge teenagers in civic engagement (Caron, 2017). Furthermore, Indonesian students watched vlogs to improve their pronunciation, enhance their listening skills, and learn new vocabulary. They learned by pausing in-between videos, opening the dictionary to search for the meaning of terms, and avoiding vlogs with subtitles to develop their listening skills (Safitri \& Khoiriyah, 2017). Thus, vlogs received positive responses from these students through learning the English language in an informal context outside the classroom (Combe \& Codreanu, 2016; Lindgren, 2011). As a result, Combe and Codreanu (2016) asserted that vlogging offers an opportunity for learners to practice speaking skills, digital literacy skills, multilingual peer learning, opinion conflicts through cultural stereotypes, and intercultural skills informally. That is why they encouraged more research to have a deeper understanding of the potential of vlogs' belongingness in the teaching-learning environment.

On the other hand, on exploring the linguistic features in the vlogs of both men and women YouTube vloggers, hedges appeared to be the commonly used feature. Hedging involves using modal auxiliaries and discourse markers to show confidence or uncertainty, express opinion, start a discussion, and use them as an ordinary filler (Nabilah, 2019). In addition, when it comes to female vloggers describing summer-make-up tutorials, the language features such as fillers or lexical hedges, precise color terms, intensifiers, emphatic stress, empty adjectives, and hypercorrect grammar manifested (Lunaeldira, 2018). These studies further imply that there are manifestations of linguistic features in vlogging that could make it an avenue for a speaker to practice his speaking skills.

Despite the positive atmosphere of YouTube, there exist negative-affect vlogs such as crying vlogs and anxiety vlogs. Mostly, female vloggers have indulged in this genre of vlogging in which they express their disappointments, anger, and pain about their struggles. Crying vlogs involve confessing struggles and pains while anxiety vlogs include raising awareness in dealing with panic attacks and strengthening mental health. Although these negative-affect vlogs have not attracted many viewers compared to other genres, the intimacy established by the vloggers and viewers is its interesting feature. Thus, crying and anxiety vlogs can create an intimate digital viewer considered an important breakthrough in the culture of YouTube vlogging (Berryman \& Kavka, 2018).

Thus, to explain how YouTube vlogs affect a wider audience, the Media Multiplexity Theory developed by Caroline Haythornthwaite in 2011 speaks that one's exposure to media depends on one's purpose of using it. The theory further states that more prolonged exposure to media creates a more significant impact than those who have shorter exposure. Therefore, those who often use vlogs for learning or entertainment will have a greater tendency to be exposed to their conventions and practices than those who rarely use them. That is why Werner (2012) stressed that involving learners in vlogging comes with significant risks. Although some researchers asserted that vlogging could improve speaking skills, learners must become literate enough to understand the pros and cons of indulging in this digital trend. Sharing experiences and opinions on the internet is like opening the door for criticism and judgment, aside from gaining compliments or support. Also, Gallardo (2014) stressed 
that Millennials, although dubbed as digital natives, are knowledgeable in using mobile phones and other technology for social communication and personal interactions, but not experts in using them for educational purposes. Therefore, Werner advocated immersive participation in which learners learn first the convention of vlogging before they create their vlogs.

As a whole, this chapter presents the discussion of topics and concepts concerning the study at hand. This chapter presents the theoretical background (the study of pragmatics, politeness and impoliteness taxonomy, and speech act theory), studies about politeness strategies in spoken media (positive, negative, bald on-record, and off-record politeness), the aftereffects of using politeness strategies, and the popularity of vlogs (through the lens of various researchers).

\section{Methodology}

\subsection{Research Design}

This study employed qualitative research design such as content analysis and phenomenological study to understand the politeness strategies used by YouTube vloggers in reaction vlogs, and how the politeness strategies they used influence viewers. Content analysis was employed to answer the first research question in which the research participants and I identified and analyzed the politeness strategies in the five vlogs we viewed. On the other hand, a phenomenological study used helped answer the second research question containing further explanation on its influence on the participants. In general, qualitative research "is a holistic approach that involves discovery. Qualitative research is an effective model that occurs in a natural setting that enables me to develop a level of detail from high involvement in the actual experiences" (Creswell, 2012). As I viewed YouTube vlogs as records of people's varied life experiences, I used the qualitative method.

In addition, content analysis is one of the main methods used to analyze message content classified under qualitative descriptive research design. Accordingly, "content analysis assumes that the messages (texts) are the phenomena to be examined and provide the units of data collection" and is generally defined as the "systematic, objective, quantitative analysis of message characteristics" (Neuendorf, 2019). Technically speaking, the results of qualitative content analysis are numbers and percentages as it involves establishing categories and determining the number of frequencies of its occurrence in a particular type. Qualitative content analysis "is a method of data analysis that involves categorizing and quantifying the characteristics of qualitative data." Thus, the frequencies are considered essential for the development of a category or theme (Marks \& Yardley, 2004). Hence, as I aimed to determine the number of instances YouTube vloggers use the four politeness strategies based on the analysis of the research participants, qualitative content analysis was utilized. Moreover, to answer the second question, which was about trying to find how these strategies influence viewers, I employed a phenomenological study. The phenomenological study deals with the study of how people find their experiences meaningful. In this research, I listened to people's recount of significant experiences in describing the appearance of things as lived experiences (Baraceros, 2016).

Furthermore, as I gathered videos from YouTube sites, the corpora were established. Corpus linguistics approaches the study of language in use through corpora (singular: corpus). "A corpus is a large, principled collection of naturally occurring examples of language stored electronically" (Bennett, 2010). Most corpus linguists are unwilling to answer if corpus linguistics is a methodology or theory, but in analyzing language using corpora, there is a method to employ. The Corpus Approach has four significant characteristics (Biber, Conrad, \& Reppen, 1998). The Corpus Approach must be empirical, utilize a large and principled collection of natural texts, make extensive use of computers, and depend on quantitative and qualitative analytical techniques. Moreover, there are various types of corpora, but one could create own corpora through adhering to its principles. "The corpora must be principled, must use authentic texts, and must have the ability to be stored electronically" (Bennett, 2010). In doing so, accordingly, a corpus is principled if not chosen randomly but according to specific 
Analysis of politeness strategies in Youtube reaction vlogs

characteristics. Secondly, the corpora must use authentic texts used for real communicative purposes. Lastly, the corpora could appear electronically like that of text format or web-based format for easy accessibility in the classroom.

In addition, there are three genres of text in making a corpus. These genres include written corpus, speech corpus, and spoken corpus. In this study, as I created corpora of YouTube video vlogs, the genre used is speech corpus. "Speech corpus contains all formal and informal discussions, debates, previously made talks, impromptu analysis, casual and normal talks, dialogues, monologues, various types of conversation, online dictations, instant public addressing, etc." (Dash, 2010). One crucial aspect in establishing the corpora of this research was the permission and legal accountability in using vlogs as the data source. To address these concerns, I iterated that YouTube is an open-access site that archived contributions like vlogs. Thus, vloggers knew and should regard that any content they upload on YouTube is "public". It means belonging to the community and being open to all people, especially to me, the researcher. With this, individual consent may not be required (British Association for Applied Linguistics, 2006).

Furthermore, to support the claim that there is no need for consent for the collection of the data source in this research, Bruckman (2002) proposed the criteria for Public-Private Distinction, a way of deciding if online content should be considered "public" or "private." Accordingly, to be considered public, online content must be "officially, publicly archived, no password required for archive access, no site policy prohibits it, and the topic is not highly sensitive." As such, online content is considered "public," "freely quoted and analyzed," and "without consent." Therefore, as I found YouTube and YouTube vlogs coalescing to these criteria, they are considered "public" along with other online platforms such as Twitter and Facebook. As a whole, this research employed qualitative research design such as content analysis and phenomenological study in analyzing the corpora of YouTube reaction vlogs to determine the usage of politeness strategies and how these strategies influence viewers.

\subsection{Research Corpora and Participants}

The research corpora comprised five reaction vlogs. Reaction vlogs were video contents composed of reactors and content/topic reacted on. In the selection of reaction vlogs, the criteria include (i) real experts in various fields of practice, (ii) vlogs with thousands to millions of views and subscribers, and (iii) reactors who used the English language as the medium of communication. Specifically, in this study, the reactors were composed of an actual doctor, priest, chefs, engineer, and marines reacting to drama and movie scenes, song/music video, technology, and online game related to their field of expertise or profession.

The first reaction vlog came from Doctor Mike (2018), where he reacted to the season 1 episode 1 of the medical drama The Good Doctor that garnered over 24 million views on YouTube. Second, in the vlog owned by a duo named Jolly (2018), a priest reacted to the controversial song God is a Woman by Ariana Grande that had over nine million views. Third, the vlog uploaded in the channel BuzzFeedVideo (2018) showed four chefs reacting to cooking movie scenes currently viewed by more than four million people. The fourth vlog uploaded by an engineer named Pary Chahal in his channel The Gold Life (2019) with over 600,000 views where he reacted to the technology used in the Iron Man movie. Lastly, the fifth reaction vlog of two female marines reacting to the online game Call of Duty WWII and uploaded by Gamology (2020) had almost one million views.

Furthermore, the research participants in this study were 14 English language teachers, seven participants with master's degrees, and seven with bachelor's degrees. They were selected using purposive non-random sampling, considering the purpose of this research to determine the politeness strategies used in reaction vlogs and how these strategies influence viewers. Purposive sampling, also known as judgmental, selective, or subjective sampling, is a non-probability sampling technique in which participants were selected according to the researcher's selection criteria based on the purpose of the study (Sharma, 2017). As suggested by Creswell (2013), there are five to 25 individuals required for purposive sampling in a phenomenological study. With 14 
English language teachers as research participants, this research followed the required number of participants.

In light of the number of participants, I examined the characteristics and attributes they should possess for them to participate in the study. Hence, I set the inclusion criteria and exclusion criteria in the selection process. These criteria helped to minimize the withdrawal of subjects that may compromise the timely fulfillment of the research objectives. Primarily, inclusion criteria refer to the essential attributes that make research subjects qualified to participate. Thus, in this research, the research participants must be (i) English language teachers with at least a master's degree or bachelor's degree, (ii) currently teaching at a secondary school or college/university, (iii) well-informed and knowledgeable about Brown and Levinson's theory of politeness strategies, (iv) familiar with YouTube as a social media platform, and (v) have watched vlogs before or exposed to vlogging phenomenon. With these qualifications and their expertise in language teaching, I ensured the quality and validity of their responses.

Consequently, 14 participants met the inclusion criteria and I divided them into two groups. Seven participants participated in the in-depth interviews and the other seven participants in focus group discussion. Since there should be at least six participants for in-depth interviews and focus group discussion, the distribution of the participants in these two types of interviews has been followed and was enough to elicit themes (Mason, 2010). Furthermore, the setting of exclusion criteria was equally important to establishing the inclusion criteria. Exclusion criteria pertain to the responses of the subjects of the study that requires their removal as participants. Since the most critical part of this study was the analysis of politeness strategies, participants who did not know or refused to know Brown and Levinson's politeness theory cannot participate in the study. Most importantly, since this research did not wish to pressure participants and compromise their well-being, they may refuse to participate in the study. The refusal to participate did not involve a penalty or loss of benefits. They may withdraw their consent at any time and discontinue participation without liability.

\subsection{Data Collection}

There were several processes undertaken in this research. To commence, I thought of a topic that would be meaningful and doable. Upon the go signal of my research adviser, the research journey finally began. Then, I indulged in careful planning and settled preliminary activities needed. Afterward, I sent a letter to the concerned authorities and consent forms to the research participants, and proceeded to data collection and interview. Before the actual interview, I had to build the corpora of vlogs taken from the YouTube site. The vlogs comprised of legit professionals in the field of health, priesthood, engineering, military services, and the food industry. I verified the authenticity of the reactors as professionals by searching their names and profile on Google sites. Then, I saved all videos on a computer and ensured backup files for safekeeping purposes. I prepared the printed script of the reactors' utterances in each vlog by watching and listening to the videos several times. This was to ensure that the participants had a clearer understanding of the vloggers' utterances in the whole duration of the vlogs.

Next, after gaining permission and establishing the corpora, I conducted in-depth interviews and focus group discussion. During this pandemic, I interviewed the 14 participants, observing the minimum public health protocols mandated by the government through the Omnibus Guidelines on the Implementation of Community Quarantine. As a result, I interviewed the seven participants for in-depth interviews using phone calls, email, and/or face-to-face interaction as they preferred to. These were the feasible options yet since I lived in a rural area where internet connection was precarious, thus, the widely used video conferencing was not an effective method. On the other hand, since the government has allowed mass gathering to $50 \%$ venue capacity under Modified General Community Quarantine (MGCQ) areas, the remaining seven participants for focus group discussion were interviewed in one classroom/venue through face-to-face interaction. Clearly and strictly, I followed health standards mandated by the government during the interviews.

In addition, on the interviews, to maintain ease and a non-threatening environment, I made sure to establish 
Analysis of politeness strategies in Youtube reaction vlogs

rapport with the participants to avoid awkward moments that would hinder gaining accurate responses. However, although participants indulged in a comfortable set-up, as a researcher, I also made sure to take control of the questioning process to keep everything on track and in line with the research purpose. In addition, aside from the use of a recorder, I wrote my observations in a journal notebook about their feelings and expressions that prevailed during the interviews in support of the data transcribed from the recorded media. Finally, after retrieving the recorded interviews, the responses were transcribed in verbatim fashion accordingly. I presented the collected data and treated it with confidentiality. These were analyzed, explored, documented, and treated as what this study required. Moreover, studies and related literature helped to support and validate the data collected.

\subsection{Data Analysis}

This study used Brown and Levinson's taxonomy of politeness in the analysis of politeness strategies used in the five reaction vlogs. There were four politeness strategies called positive Politeness, negative Politeness, bald-on record Politeness, and off-record Politeness. I tallied, identified, examined, and scrutinized the actual utterances of vloggers to any of these four classifications based on the specific strategies exhibited by the vloggers/reactors with the help of seven competent research participants who were at least master's degree holders. After the analyses and shared elaboration, through content analysis, I computed the number of frequencies and percentages of such strategies manifested by the vloggers. Moreover, on the second research question about how politeness strategies in reaction vlogs influence viewers, I interviewed 14 participants who shared their experiences, realizations, and insights through phenomenological research inquiry. I transcribed the recorded data and translated the vernacular responses into the English language. Then, I built the themes and codes based on their responses.

Creswell (2008) enumerated six steps in the data analysis of qualitative research. These steps include (i) organize and prepare the data for analysis, (ii) read or look at all data, (iii) start coding all of the data, (iv) generate a description of the setting or people as well as categories or themes for analysis, (v) convey the findings of the analysis through a narrative passage, and (vi) make interpretation of the findings. Firstly, I organized and prepared the data for analysis. The procedures include transcribing data, scanning materials, sorting, and arranging data into different types depending on the sources of information. In this stage, it was very essential to be vigilant in transcribing and meticulous in sorting data. Secondly, I read or looked at all the data. In this stage, I provided a general sense of the information and reflected on its overall meaning. This action was challenging since synthesizing data required a dedicated amount of time and thinking. Hence, in this stage, I wrote notes and start recording general thoughts about the data.

Thirdly, I started coding all of the data. Coding is the process of taking text data or pictures gathered during data collection, segmenting sentences or paragraphs or images into categories, and labeling those categories with a term often based on the participants' language. In making codes, Creswell suggested providing codes on topics that readers would expect to find, codes that are surprising and unexpected, and unusual codes and of conceptual interest to readers. The fourth step was using the coding process to generate descriptions, identify themes, and form complex theme connections. In this stage, I supported the themes with diverse quotations and specific evidence. Creswell suggested having five to seven themes for a research study. Fifth, I conveyed the findings of the analysis through a narrative passage. According to Creswell, this discussion might be through mentioning a chronology of events, a detailed discussion of several themes packed with sub-themes, specific illustrations, multiple perspectives from individuals, and quotations, or a discussion with interconnecting themes. Some researchers also use visuals, figures, or tables to convey the findings. In doing so, I presented a detailed discussion of the theme and its sub-themes.

Lastly, I interpreted the findings or results. This interpretation was based on the reflection and meaning derived from the comparison of findings. I also stated implications of research and further questions to ask, call for action agendas for reform and change, or describe how the narrative outcome reinforced the theories and the 
Alcosero, I. R., \& Gomez, D.

general literature on the topic. Furthermore, I encoded the transcriptions in the computer for safekeeping and analysis. Back-up files ensured that copies will be safe. Then, the data analyst checked the validity and accuracy of the analysis and interpretation of the results.

\section{Results}

The analyses and interpretation of the results were taken from the in-depth interviews and focus group discussion arranged based on the order of the research questions presented in Chapter 1. Mainly, the study's objectives were drawn to answer the following questions.

$>\quad$ What are the politeness strategies used in YouTube reaction vlogs?

$>$ How do these politeness strategies in YouTube reaction vlogs influence viewers?

Key Informants. There were 14 key informants in this study, seven males and seven females, who are English language teachers, with at least master's degrees and bachelor's degrees, within the age range of 24-35 in two schools in Davao de Oro Division and one school in Division of Tagum City. After the Schools Division Superintendents approved the permission to conduct the study, I went to the School Heads to endorse the names of the teachers subjected to interviews. They were selected by their willingness to be interviewed and their competence to provide relevant inputs and analyses on politeness strategies in reaction vlogs. Then, the participants were fully protected by the Data Privacy Act of 2012 or RA 10173. The participants' confidentiality and anonymity were kept to not put them at risk by using pseudonyms or aliases. This is stipulated in Ethical Considerations in Chapter 3 and is presented in Table 1.

Focus Group. The Focus Group Discussion (FGD) was also used to gather thorough analyses about the research topic through meaningful discussion and consolidation. There were seven participants in the focus group. For this study, the FGD was conducted in one meeting upon the schedule date approved by each participant. It was advantageous and convenient because I could convene with seven people who all came to one school. Since the participants were already acquainted, the smooth flow of sharing was evident as participants were comfortable with each other and the atmosphere established in the interview setting. The interviews were conducted through phone calls and face-to-face interaction. For in-depth interviews, I individually called the seven participants and recorded our conversations. Since using some of the popular online meeting platform today such as Google Meet, Zoom, Skype, and Room via Messenger were not feasible in my location, and to most of my participants, I opted to use phone calls. For focus group discussion, face-to-face interview was conducted following the minimum public health protocols such as wearing of face masks, maintaining social distancing, and allowing only eight people in the interview area which adhered to the $50 \%$ venue capacity accepted for mass gathering in modified general community quarantine (MGCQ) areas.

\section{Table 1}

Participants' Information on the conduct of Interviews

\begin{tabular}{lcccc}
\hline \multicolumn{1}{c}{ Pseudonym } & Age & Gender & Educational Level & Study Group \\
\hline Red & 24 & Male & MAED-English & In-depth Interview \\
Orange & 24 & Female & MAED-English & In-depth Interview \\
Yellow & 26 & Female & MAED-English & In-depth Interview \\
Green & 25 & Female & MAED-English & In-depth Interview \\
Blue & 24 & Female & BSED-English & In-depth Interview \\
Indigo & 22 & Male & MAED-English & In-depth Interview \\
Violet & 25 & Female & BSED-English & In-depth Interview \\
Daisy & 25 & Male & MAED-English & Focus Group \\
Rose & 25 & Male & BSED-English & Focus Group \\
Jasmine & 26 & Female & BSED-English & Focus Group \\
Daffodil & 26 & Male & BSED-English & Focus Group \\
Dahlia & 35 & Male & BSED-English & Focus Group \\
Orchid & 30 & Female & BSED-English & Focus Group \\
Lily & 28 & Male & MAED-English & Focus Group \\
\hline
\end{tabular}

116 Consortia Academia Publishing (A partner of Network of Professional Researchers and Educators) 
4.1 Research Question No. 1. What are the politeness strategies used in YouTube reaction vlogs?

In analyzing the politeness strategies used in the vlogs, Brown and Levinson's taxonomy of politeness (1987) was used. Thus, the tabular data showed the presentation of politeness strategies according to its four classifications, namely: positive Politeness, bald on-record Politeness, off-record Politeness, and negative Politeness. Me and the seven research participants interpreted the verbal reactions of the vloggers through citing lines and phrases uttered by each vlogger/reactor. Then, the number of frequencies and percentage were also presented to compare the dominant and least used politeness strategies. Noticeably, upon the analysis, some vloggers did not use all types of politeness strategies in giving their reactions. Thus, the frequencies and percentage were zero, and the sample utterances column were left blank. Furthermore, me and the seven research participants' shared elaboration and discussion during the analysis phase of this study were presented as support to the tabular presentations. Aside from scrutinizing the vloggers' verbal utterances, their non-verbal reactions like facial expressions, gestures, posture, tone, pitch, and volume were also examined and discussed. Thus, relevant-sided explanations were presented to shed further light on the classification of utterances according to the four politeness strategies.

Overall, there were six tabular presentations in realizing the first research questions corresponds to the number of reaction vlogs and its summary. The first reaction vlog was made by a real doctor reacting to a medical drama, The Good Doctor. It is a reaction video that had about 15 and half minute duration. Doctor Mike, the reactor, watched the season 1, episode 1 of the show and reacted on the medical procedures performed by the characters and shared medical information to his viewers.

Table 2

The frequency and distribution of politeness strategies used in YouTube reaction vlog 1

\begin{tabular}{|c|c|c|c|}
\hline $\begin{array}{l}\text { Politeness } \\
\text { Strategies }\end{array}$ & Frequency & Percentage & Sample Utterances \\
\hline Positive & 35 & $58 \%$ & $\begin{array}{l}\text { I'm not gonna lie. I agree with the president on that. } \\
\text { I appreciate the show highlights that. } \\
\text { I like him cause he's superhuman and knows everything but it's } \\
\text { just so unrealistic. But I understand that they need that factor to } \\
\text { make the show work. }\end{array}$ \\
\hline Bald on-Record & 20 & $33 \%$ & $\begin{array}{l}\text { The more I think about what he did there in the airport, the } \\
\text { more I think it's inappropriate. } \\
\text { Don't take it out! Don't take it out! } \\
\text { That's not the right way to do it. }\end{array}$ \\
\hline Off-Record & 3 & $5 \%$ & $\begin{array}{l}\text { I mean, how about getting him to sign all the paper works and } \\
\text { disclosures and hippo forms, and making sure he has } \\
\text { identification? } \\
\text { Is this the same security guard who knows everywhere he's } \\
\text { gonna go? Maybe this guy is a savant too? } \\
\text { Is he gonna go to the second or fourth intercostal space? }\end{array}$ \\
\hline Negative & 2 & $3 \%$ & $\begin{array}{l}\text { Could be a surgeon, I don't know yet. } \\
\text { I don't know what they're debating about the cavity. That's } \\
\text { open for interpretation. I never seen a situation like this. }\end{array}$ \\
\hline Total & 60 & $100 \%$ & \\
\hline
\end{tabular}

In the first reactor (Doctor Mike), all four politeness strategies were used. There were 35 utterances that used positive Politeness (58\%), 20 utterances for bald on-record Politeness (33\%), three utterances for off-record Politeness (5\%), and two identified utterances for negative Politeness (3\%). Overall, there were 60 identified utterances of the first reactor that used all four politeness strategies of Brown and Levinson. In the 35 positive politeness utterances, the reactor used the sub-strategies finding agreement (15), giving rewards to hearers (10), giving or asking for reasons (7), avoidance of disagreement (2), and joking (1). Then, these findings were supported by the statements of the participants who helped in the analyses. 
Green (pseudonym) declared:

"He uses positive politeness by giving compliments 'That's impressive. That's actually accurate. It's fairly medically accurate. The drama in the show is interesting' and conformity 'I agree.", (MAED-04)

Similarly, Lily (pseudonym) observed:

"Doctor Mike used positive politeness through agreeing to what is presented in the drama by saying 'It's a good advice, that's impressive, I agree with the president.'” (MAED-07)

Pertaining to the main character of the drama and the people behind the scenes like the directors, writers, and the rest of the production staff, Red (pseudonym) imparted these statements on how the doctor showed his reaction in the medical drama:

"Another line 'I will say however, that they almost make him look superhuman and that's not realistic so that's definitely a con in my book. But I understand that they need that factor to make the show work.' This is rather polite for me, it's the positive politeness." (MAED-01)

Furthermore, Yellow (pseudonym) expressed why the reactor tend to give reasons and explanations to the technical aspects of the medical operations in the drama:

"Doctor Mike is using positive politeness because he is trying to give reactions to the video according to his profession. He is a doctor so he knows the technical terms for the process of having that kind of emergency. In that video, the main actor is trying to save a certain person, Doctor Mike uses his knowledge about the technical terms, apparatus, equipment, materials used in that certain emergency situation. The doctor also is trying to say approval with what the main actor is doing. (MAED-03)

Lily (pseudonym) expressed his feeling toward the reactor giving further explanation of what the actor was doing:

"He tried to explain it one-by-one. He also tried to explain things that are not realistically correct. It can really influence you or convince you that they are doing truthful things in the medical drama and the doctor explains it one-by-one. I think that's great". (MAED-07)

Pertaining to the reactor's usage of positive politeness, Green (pseudonym) shared:

"The dominant strategy, which is positive politeness, his way of giving suggestions and sharing his thought in a way that it did not directly offend online viewers reflect his professionalism". (MAED-04)

Secondly, out of 20 utterances used by the reactor under bald on-record Politeness, the following sub-strategies were used: maximum efficiency (8), giving task-oriented way of instruction (7), and giving sympathetic advice or warnings (5). These were the statements that explain why bald on-record Politeness were used by the reactor.

Green (pseudonym) observed:

"There are, however, less attempt to redress threats to the hearer's negative face. There was direct imposition to hearer's freedom of action in the lines 'You need to..., That is not perfect. Never pull it out!'” (MAED-04)

Indigo (pseudonym) further reasoned: 
"His frequent use of bald on record politeness is acceptable. For example, about the protagonist blowing his gloves through his mouth like "That's not perfect" it is quite impolite but is interpreted as bald on record because I could set aside my face wants just to cater his idea which I think is also sound and acceptable." (MAED-05)

More so, Indigo (pseudonym) added:

"There is some bald on record just like when the doctor shouted, 'Do not take it out.' He said it while shouting." (MAED-05)

Orange (pseudonym) affirmed:

"Bald on record also. Naa siyay command nga iyang ginabuhat which is bald on siya like 'Put your mask on. Don't take it out.", (MAED-02)

(Bald on record also. There is a command being done which is bald on like "Put your mask on. Don't take it out.")

Indigo (pseudonym) also cited lines from the vlog where warning was explicitly expressed:

"You need to be a lot more careful cause this isn't just a game, it's people's life at risk." (MAED-05)

Thirdly, in the three off-record politeness utterances, two sub-strategies were used. These are using rhetorical questions (2) and giving association clues (1). Off-record Politeness was used by the reactor to indirectly tell viewers to do something. The reactor asked questions and let the viewers interpret his utterances and do something about them.

When the reactor used rhetorical question that was employed to add effect and impact but did not require answer from the viewers, Lily (pseudonym) cited and explained:

"'Is this the same security guard who knows everywhere he's gonna go? Maybe this guy is a savant too?', the priest leaves the interpretation to the audience." (MAED-07)

However, when the reactor attempted to give the viewers clue on the right procedures in medical field, Indigo (pseudonym) cited the lines:

"How about getting him to sign all the paper works and disclosures and hippo forms, and making sure he has identification?" (MAED-05)

Lastly, in the two utterances under negative politeness, the reactor used the sub-strategy being pessimistic (2). Indigo (pseudonym) cited the lines:

"'Could be a surgeon, I don't know yet.' 'I don't know what they're debating about the cavity, I never seen a situation like this.", (MAED-05)

Furthermore, negative politeness is also known as respect politeness in which utterances were used to give formality and restraint in conversation.

Lily (pseudonym) imparted:

"When pointing out scenes with exaggerated medical approach, he states facts in a declarative manner; but he shows respect based on his tone and facial expression." (MAED-07)

Indigo (pseudonym) added: 
"There are few negative politeness utterances he backed with sound reason. Unlike the priest, he is more spontaneous with his politeness. It comes naturally unlike the priest who is nervous and very careful, he is spontaneous." (MAED-05)

Table 3

The frequency and distribution of politeness strategies used in YouTube reaction vlog 2

\begin{tabular}{|c|c|c|c|}
\hline $\begin{array}{l}\text { Politeness } \\
\text { Strategies }\end{array}$ & Frequency & Percentage & Sample Utterances \\
\hline Positive & 18 & $51 \%$ & $\begin{array}{l}\text { I think that is probably a true statement. } \\
\text { Oh my dear, I really like the beat, but I'm not sure about the } \\
\text { lyrics. } \\
\text { The Bible is clear that those who are in the sense of teaching } \\
\text { have a right to reprove and rebuke and lovingly guide those } \\
\text { who aren't. }\end{array}$ \\
\hline Bald on-Record & 9 & $26 \%$ & $\begin{array}{l}\text { So yeah, Ariana. Better check yourself before you wreck } \\
\text { yourself.. } \\
\text { If anyone knows, please explain. } \\
\text { No, there is no, there is no gender in the Trinity. }\end{array}$ \\
\hline Off-Record & 6 & $17 \%$ & $\begin{array}{l}\text { But yeah, I think at the beginning, she's talking to like, a } \\
\text { boyfriend or you know, hopefully a husband, hello? } \\
\text { You'll believe god is a woman? So, she's not saying... Okay } \\
\text { Oh my gosh! Look at that! Is that meant to be? Oh dear. }\end{array}$ \\
\hline Negative & 2 & $6 \%$ & $\begin{array}{l}\text { I'm not saying I'm the font of all knowledge. } \\
\text { I don't know it off by heart. }\end{array}$ \\
\hline Total & 25 & $100 \%$ & \\
\hline
\end{tabular}

The duo Jolly made the second reaction vlog who invited Reverend Chris to respond to the song God is a Woman by Ariana Grande. The reaction vlog was a nine-minute video showing a priest reacting to the song and its music video that sounds controversial about religion and faith. Since it was the first time that the priest heard the song and he guested in Jolly, excitement and shock were evident but turned out to be a natural and light discussion. The second reactor, Father Chris, have used 35 politeness utterances. Out of which,18 utterances were categorized to positive Politeness $(51 \%)$, nine utterances for bald on-record $(26 \%)$, six total utterances for off-record (17\%), and two negative politeness utterances $(6 \%)$. Just like the first reactor, all four politeness strategies were used by the second reactor.

Firstly, in the 18 positive politeness utterances, the following sub-strategies were used: finding agreement (5), giving rewards to hearers (5), giving or asking for reasons (5), and avoidance of disagreement (3). These were expounded by the careful analyses with the help of the seven knowledgeable participants.

Yellow (pseudonym) described:

"He is trying to restrict the things he wanted to say for that video. The priest wanted to express himself but because he is afraid that he might say something that would offend Ariana and the fans and because of his profession as a priest, he is not allowed to say mean words." (MAED-03)

Red (pseudonym) asserted:

“'The priest is neutral. He is not imposing nor is he threatening the self-image of Ariana Grande; but rather he is just giving a cognizant opinion in terms of what his experiences dictate. For me, he's kind of neutral.” (MAED-01)

Lily (pseudonym) added:

"He tried to explain accurately based on his learning from the Bible. He tried to explain 
presenting it based on the theological learning that he has and giving his reaction in positively polite way and not attacking Ariana Grande." (MAED-07)

Daisy (pseudonym) expressed:

"He's a priest in profession, accordingly, but he was not there to give the judgement, that final verdict to Ariana. He was not there to close the idea for the audience that God is not really a woman." (MAED-06)

Similarly, Green (pseudonym) explained:

"When the priest said 'Thou shalt not judge', we all know that he is a priest so it's normal for the priest to say that to the viewers that we shall not judge a person because he thinks that it is not the idea of Ariana Grande alone." (MAED-04)

Red (pseudonym) added:

“'Ariana Grande, bless you. I wouldn't say God is a woman. God is neither a man. God is loving.' This kind of reaction for me is a redress. You are not reprimanding but you are doing like that. You are trying to say something negative, but at the same time you are making up for that negative reaction by saying something positive." (MAED-01)

Secondly, when it comes to bald on-record politeness, the sub-strategy giving sympathetic advice or warnings (5), maximum efficiency (3), and giving task-oriented way of instruction (1) were used. There was a total of nine direct utterances of the reactor. Generally, in this study, bald on-record Politeness that conveys direct and clear utterances were used to express warnings, emphasize the urgency of the message, and give a command. The following statements were told during the analyses.

Orange (pseudonym) explained:

"Kuan pud, si reverend father pud, ning-ana siya 'So yeah, Ariana. Better check yourself before you wreck yourself.'. It is for me nga murag nag-warn siya mao nang bald on record akong ma-categorize nga statement ni reverend priest." (MAED-02)

("Also, reverend father said 'So yeah, Ariana. Better check yourself before you wreck yourself". It is for me like he warns so I categorized the statement of reverend priest as bald on record.)

Daisy (pseudonym) also conveyed:

"The priest is explaining the real meaning of the quote taken from the Bible. 'Yeah, she's misquoting scripture which is actually quite dangerous because it does say at the end of the Bible, don't misquote it.", (MAED-06)

Lily(pseudonym) observed:

"But to the hearers, he made clear that there is no gender in God." (MAED-07)

For instance, Orange (pseudonym) cited the line:

"When the priest said, 'It's not biblical." He directly confronts the idea and lets people know about it. He expressed his thought as if its urgent and people should not be mislead." (MAED-02)

Thirdly, six utterances categorized in off-record Politeness utilized the following sub-strategies: using rhetorical questions (5) and giving association clues (1). The reactor used these to take away the responsibility of what the viewers might think by giving them leeway to interpret and give meaning to his utterances. 
For instance, Lily (pseudonym) expressed:

"The priest tried to be indirect as much as possible by putting the interpretation to the audience through asking questions like, 'Look at that! Is that meant to be? What is the relevance of the gophers? If anyone knows, please explain.'” (MAED-07)

Green (pseudonym) also explained:

"'But yeah, I think at the beginning, she's talking to like, a boyfriend or you know, hopefully a husband, hello?' Dili siya sure kung kinsa ang gi-mean ni Ariana. But in a way, he gives the viewers a message or clue that intimacy should be shown in marriage." (MAED-04)

("But yeah, I think at the beginning, she's talking to like, a boyfriend or you know, hopefully a husband, hello?" He is not sure who is Ariana referring to. But in a way, he gives the viewers a message or clue that intimacy should be shown in marriage.)

Interestingly, the participants also observed that the vagueness and indirectness of imposition were manifested not only in the utterances of the reactor but also to their facial expressions. In fact, Red (pseudonym) exclaimed:

"I don't actually see it on his face, but on his voice." (MAED-01)

Yellow (pseudonym) affirmed:

"The priest is trying to use facial expressions like smirking, trying to make his eyes wider, so I felt like his words are somehow different from his facial expressions." (MAED-03)

Lastly, when it comes to negative politeness utterances, the sub-strategy being pessimistic (2) was manifested. It was expressed using self-doubt phrases as cited by Indigo (pseudonym) below. In this strategy, the reactor allowed doubt to lessen the impact of his imposition and to avoid being dubbed as rude and too imposing.

“'I'm not saying I'm the font of all knowledge.' 'I don't know it off by heart."” (MAED-05)

Moreover, Green (pseudonym) explained why the reactor had been very careful not to offend the singer, the fans, and the creators or production staff of the music video:

"The priest needed it most compared to the other vlogs subject to this study probably because of the nature topic. He tried to be indirect as much as possible, maintaining consciousness to Ariana's self-image. He tried to counterbalance the redressed imposition with positive politeness "I like the song. I like the beat." (MAED-04)

Further, Indigo (pseudonym) shared:

"More so, because of his attempt to take responsibility as both having the 'right to reprove and rebuke and lovingly guide' and who is careful not to judge and be judged, I think he considers as much as five factors: Ariana and her fandom, the vlog, himself as a priest, the Christians who might take his cause, and that of God. All these factors he both defend and offend as he discloses his own imposition. Not that I think he made it perfectly, but I thought maintaining his stand in such a sensitive topic with so many factors to consider was impressive." (MAED-05)

Green (pseudonym) added:

"He's being critical and expressed careful analysis." (MAED-04)

Orange (pseudonym) also affirmed:

“The priest was being critical and careful in reacting to the song." (MAED-02) 
Overall, Green (pseudonym) expressed:

"It is not hard to empathize with the priest. By profession, it is inherent that he confronts what he thinks is an outlandish remark on God, online, where people of diverse belief gather, it is fitting to be polite, though it is obviously hard for him to be partial on the things he truly believes in for the sake of politeness or for satisfying face wants. His diverse strategies reflect his professionalism and being knowledgeable while being sensitive with the hearer." (MAED-04)

\section{Table 4}

The frequency and distribution of politeness strategies used in YouTube reaction vlog 3

\begin{tabular}{|c|c|c|c|}
\hline $\begin{array}{l}\text { Politeness } \\
\text { Strategies }\end{array}$ & Frequency & Percentage & Sample Utterances \\
\hline Positive & 35 & $58 \%$ & $\begin{array}{l}\text { That's a real chef doing it. } \\
\text { Bradley Cooper is just a little too famous for me to picture } \\
\text { being a chef. } \\
\text { I did that every day. }\end{array}$ \\
\hline Bald on-Record & 16 & $27 \%$ & $\begin{array}{l}\text { That's a good way to chop your finger off. } \\
\text { It's not fun but it's rewarding some time. } \\
\text { That's rather extreme. }\end{array}$ \\
\hline Off-Record & 1 & $2 \%$ & $\begin{array}{l}\text { There're so many great versions out there. How can you be } \\
\text { better? }\end{array}$ \\
\hline Negative & 8 & $13 \%$ & $\begin{array}{l}\text { I don't know like that's crazy. I don't know how you reach that } \\
\text { point, that breaking point. } \\
\text { This was almost unrealistic for movie scene. } \\
\text { Well, that was a little dramatic. }\end{array}$ \\
\hline Total & 60 & $100 \%$ & \\
\hline
\end{tabular}

The third vlog was uploaded by BuzzFeed Video showing four chefs, two males and two females, reacting to seven cooking movie scenes. It has a six-minute and 53-second duration. In the vlog, the chefs commented on the realness of the various aspects and techniques of cooking portrayed in the movie scenes and shared their experiences in the kitchen. Upon the analyses, there were 60 utterances of the reactors in the third vlog that used politeness strategies. Specifically, 35 utterances were categorized under positive Politeness (58\%), 16 utterances for bald on-record Politeness (27\%), one utterance for off-record (2\%), and eight utterances for negative Politeness $(13 \%)$. Like the two vlogs presented above, the reactors had used all the politeness strategies of Brown and Levinson.

First off, in the 35 utterances of positive politeness, the following sub-strategies were used: finding agreement (17), giving rewards to hearers (17), and joking (1). In these sub-strategies, the reactors expressed agreement to the content and gave admiration and support to the movies' efforts. The following statements are presented taken from the analyses together with the seven participants.

Lily (pseudonym) explained:

"The chefs used positive politeness strategies in reacting to cooking movie scenes through giving compliments, agreeing, and giving sympathy. These are evident in the lines 'This is very food gourmet. That's impressive. That was really legit. That's a real chef doing it! I did that every day. Yeah, we do that every day with our cook. Oh, that happens to me."” (MAED-07)

Green (pseudonym) also found:

"They used positive politeness through compliments 'That's pretty impressive, that's a real chef doing it' and sympathy 'I used to work like that. I respect the people paying like 600/500 dollar a meal. Being in a food world these days is kind of like a celebrity, but behind all of that is a really tough life..., But you will still do it because you have a passion for it, there's nothing more 
Alcosero, I. R., \& Gomez, D.

rewarding than doing what you love..."” (MAED-04)

Indigo (pseudonym) shared:

"There are a lot of positive politeness strategies but sympathy is the highlight of the reaction. They even concluded with sympathy unlike most vlogs which wrapped up the good and the bad points before the "subscribe to my YouTube channel" thing. (MAED-05)

On the general atmosphere of the vlog, Daisy (pseudonym) expressed:

"The four chefs are enjoying and at the same time extending their review with jokes such as the last video that they have watched. They used smiles with good laughs on their faces as to make the hearer feel good about themselves and their interests. I also feel that they are enjoying those videos that they are watching because it all came from their experiences." (MAED-06)

In terms of bald on-record politeness, the analyses showed 16 utterances under this category. There were also two sub-strategies used that include: giving sympathetic advice or warnings (14) and maximum efficiency or being urgent and desperate (2). The utterances stem from keeping the viewers from harm and misinformation, thus, protecting their face. Here are the statements of the participants during the analyses.

Red (pseudonym) expressed:

“When Chef Joseph said, 'That's a good way to chop your finger off', for me it's bald on record.

It's kinda direct, there is no covering of the naked truth. It's what it's trying to say. It means it's a wrong way of chopping something." (MAED-01)

Apart from warning the viewers, Indigo (pseudonym) also cited a line in which the chef gave advice to aspiring chefs:

"Paying attention to every detail makes you better of paying attention to details period and it'll make you a better chef." (MAED-05)

Pertaining to the overall tone of the vlog, Yellow (pseudonym) expressed:

"They are using bald on record. They are just saying directly how they perceive that video using their expertise. They are very comfortable and honest without thinking they might offend the viewers. They are very real in giving those opinions." (MAED-03)

Thirdly, off-record Politeness was depicted in the sub-strategy giving association clues. In this strategy, the reactors wanted something the viewers to do by using indirect utterances. Specifically, in the vlog, the viewers were indirectly told to contemplate, think more profound, and evaluate their future actions. Based on the analyses, the participants had chosen this line under off-record Politeness.

"There're so many great versions out there. How can you be better? (MAED-03, MAED-04, MAED 05, MAED 06)

Lastly, in the eight utterances classified in negative Politeness, the following sub-strategies were used: being pessimistic (5) and minimizing imposition (3). In these sub-strategies, the reactors were able to lessen the impact of their imposition. As a result, they were viewed as polite instead of rude and too imposing. The following statements showed a thorough justification of the analyses.

Lily (pseudonym) expounded how minimizing imposition was used:

"When reacting to unrealistic scenes, they voice out their reactions by maintaining the self-image of the persons in the movie scenes. Instead of directly saying, 'This is unrealistic' the 
chefs said, 'This was almost unrealistic for movie scene', 'Well, that was a little dramatic.' The use of 'almost' and 'little' depicts that the chefs tried to minimize the imposition by using words, in a way, lessen the impact/intensity of the meaning of the words." (MAED-07)

On the other hand, Orange (pseudonym) explained how pessimism was manifested:

"It is also being pessimistic as I heard in the line, it says, 'Okay, I have never seen that!'. (MAED-02)

\section{Table 5}

The frequency and distribution of politeness strategies used in YouTube reaction vlog 4

\begin{tabular}{|c|c|c|c|}
\hline $\begin{array}{l}\text { Politeness } \\
\text { Strategies }\end{array}$ & Frequency & Percentage & Sample Utterances \\
\hline Positive & 19 & $49 \%$ & $\begin{array}{l}\text { So, the fact that he is able to do that without clicking any } \\
\text { button and just thinking about it is legit. } \\
\text { And I really hope I added value to the movie like I wasn't } \\
\text { trying to debunk Iron Man because I really love it. I was just } \\
\text { trying to explain how much this stuff is real and how incredible } \\
\text { the director, producers of the Marvel universe really are. } \\
\text { What's happening here is like we see he's initialized the power } \\
\text { sequence. }\end{array}$ \\
\hline Bald on-Record & 5 & $13 \%$ & $\begin{array}{l}\text { Humans are not perfect. Alright. We take imperfect } \\
\text { measurements to build imperfect tools and then we have } \\
\text { imperfect machines, like nothing about that is a hundred } \\
\text { percent. } \\
\text { I feel like you wanna cover that arc reactor with some } \\
\text { protective layering of metal so that the bullet can never get into } \\
\text { it } \\
\text { That's some serious medical emergency required right there. }\end{array}$ \\
\hline Negative & 15 & $38 \%$ & $\begin{array}{l}\text { I don't know all the uses of Palladium, but I do know that it is } \\
\text { used in jewelry, quite commonly. } \\
\text { So, I'm not actually sure how that works because the arc } \\
\text { reactor inside of him is just a really, really powerful battery. } \\
\text { I can only imagine like why that wasn't approved. That's pretty } \\
\text { horrible. }\end{array}$ \\
\hline Total & 39 & $100 \%$ & \\
\hline
\end{tabular}

The fourth vlog was made by an actual engineer named Pary Chahal uploaded in his YouTube channel The Gold Life. In the vlog, he commented on the technology used in Iron Man movies. In the vlog, the reactor disclosed that he is an avid fan of Iron Man and shared that it was the first time he watched Iron Man movies with the intent to examine how real the technology used was. Based on the results of the analyses, there were 39 utterances of the reactor. However, unlike the previous three vlogs, the reactor of this vlog did not use off-record politeness. In fact, 19 utterances were classified under positive Politeness (49\%), five utterances for bald on-record Politeness (13\%), and 15 utterances for negative Politeness (38\%).

Firstly, the analyses revealed that 19 utterances in positive Politeness were distributed to four sub-strategies. The following include finding agreement (7), giving rewards to hearers (2), giving or asking for reasons (8), and avoidance of disagreement (2). As the reactor declared being a fan, the participants cited his utterances that talked about agreement and positive response towards the technology used in the movie.

Lily (pseudonym) pointed:

"In the very first part of the vlog, the engineer disclosed the information that he is a fan of Marvel Universe and Iron Man. With this, one could expect that he would tell all the things positive to the video content. Thus, he agreed to some parts of the movie." (MAED-07)

Secondly, there were five bald on-record politeness utterances that were classified in the sub-strategy giving 
sympathetic advice or warning. In this strategy, the reactor aimed to keep the hearers away from harm and give them comfort. Relating to technology as subject, the reactor made it clear that not everything was a hundred percent possible.

Indigo (pseudonym) cited the line:

“'Humans are not perfect. Alright. We take imperfect measurements to build imperfect tools and then we have imperfect machines, like nothing about that is a hundred percent.' This line clearly shows that he is warning the viewers about the consistency and inconsistency of the technology used, and that they should be aware." (MAED-05)

Lastly, 15 utterances were identified as negative politeness strategy. These utterances were divided into two sub-strategies being pessimistic (14) and minimizing imposition (1). In the analyses, the participants expressed their positive regard as to how the reactor used pessimism smoothly and effectively in maintaining the vlog's light, informative, and entertaining atmosphere.

Particularly, Green (pseudonym) observed:

"Negative politeness is prevalent through self-effacement, self-doubt phrases 'I'm not actually sure' when he could mean 'That's wrong/false' and suggesting like 'I feel like you wanna cover the arc reactor' instead of saying 'The arc reactor should be covered'. Negative politeness is necessary, relevant, fitting for comments on the limits of technology, what's possible now with technology is impossible in the past." (MAED-04)

Similarly, Green (pseudonym) asserted:

"The reaction maintains respect and formality. FTAs are subtly wrapped with self-doubt and compliments sound believable." (MAED-04)

Furthermore, to express the effect of the phrases used by the reactor compared to other commonly used phrases, Indigo (pseudonym) explained:

"I think he is really careful not offend the fan and even the producers of the movie. To respect that identifying feature, the expert humbled his opinion through the use of 'I feel like...' and 'you want to...' phrases. When an expert uses 'I know...' it can be inferred that the expert is using the full extent of the facts he holds. With 'I think...', the expert gives an allowance for doubt and his personal responsibility for any potential error while still grounding to the facts he has. 'I feel like...', however, goes beyond the impression of being an expert and goes farther into personal responsibility, allowance for doubt, and semi-nonfactual. Also, with 'you want to...' phrase, the engineer goes below insisting to suggest a seemingly tolerable point, which runs counterintuitive to the importance of his imposition. So, according to him, the arc reactor is the weakness of the suit, instead of saying 'you need to', to be congruent with how strong his point is, to be polite, he uses 'you want to'.” (MAED-05)

Indigo (pseudonym) later gave his commendation as to how the reactor had been an excellent reactor:

"I cannot think of other ways that would accomplish the engineer's purpose better that he already did. I like how he wrapped criticism and the irrelevance of the iron-man technology by redirecting the audience into what he knows and what he does not as an engineer." (MAED-05)

Furthermore, Lily (pseudonym) shared his analyses of the utterance by pointing:

"The engineer remained fair and impartial in giving his reactions through using negative politeness techniques such as expressing self-doubt and suggesting. Expressing self-doubt in the 
lines, 'I don't understand how they can paralyze somebody. Tony might be able to integrate that into the suit itself, but I can't imagine where he would put it. I don't know the requirements for going supersonic in air when it comes to like military vehicles, I just know that current fighter jets can do I'; and suggesting in the lines, 'He needs to have some sort of way to not pass out because even the fighter pilots inside those jets are wearing masks.'” (MAED-07)

At last, Daisy (pseudonym) exclaimed:

"'The only thing I can't wrap my head around is how Iron Man is able to fly', negative politeness siya sa kani nga part." (MAED-06)

("The only thing I can't wrap my head around is how Iron Man is able to fly." This part is negative politeness.)

Table 6

The frequency and distribution of politeness strategies used in YouTube reaction vlog 5

\begin{tabular}{|c|c|c|c|}
\hline $\begin{array}{l}\text { Politeness } \\
\text { Strategies }\end{array}$ & Frequency & Percentage & Sample Utterances \\
\hline Positive & 4 & $11 \%$ & $\begin{array}{l}\text { That gonna be } 400 \text { yards or so. } \\
\text { I had a lot of fun watching it. } \\
\text { I would've like to see him use the other weapons like he had a } \\
\text { lot to choose from. }\end{array}$ \\
\hline Bald on-Record & 8 & $22 \%$ & $\begin{array}{l}\text { Come on bro, please wear your shirt. } \\
\text { Oh, the air quality in this game is terrible. } \\
\text { It's gonna be really cumbersome and running with that kind of } \\
\text { gear is just unrealistic }\end{array}$ \\
\hline Off-Record & 22 & $59 \%$ & $\begin{array}{l}\text { It's so funny. Just watching it like this is nothing at all. } \\
\text { Good job going from place to place, just shooting everything in } \\
\text { your path. } \\
\text { I love how it tells you where everything stocks. Super store, } \\
\text { train station. }\end{array}$ \\
\hline Negative & 3 & $8 \%$ & $\begin{array}{l}\text { I don't think that's how it works. } \\
\text { I don't know why that's there. I didn't have a dog key chain on } \\
\text { my weapon. } \\
\text { The graphics are a little cheesy. }\end{array}$ \\
\hline Total & 37 & $100 \%$ & \\
\hline
\end{tabular}

The fifth and last reaction vlog subjected for analyses in this study was uploaded by Gamology, showing two female marines reacting to the online game Call of Duty: Warzone. The video ran six-minute and 12-second. Basically, in the vlog, the reactors commented as to how the game proved to be realistic or not as far as their experiences in the military field dictate. In the tabular presentation, the analyses revealed that there were 37 polite utterances in the last vlog. There were 4 utterances classified in positive Politeness (11\%), eight utterances in bald on-record (22\%), 22 utterances in off-record Politeness (59\%), and three utterances in negative Politeness $(8 \%)$. Unlike the reaction vlog 4 (engineer as reactor), this vlog had used all four politeness strategies of Brown and Levinson.

First, in the 4 utterances categorized in positive politeness (see Appendix I), two sub-strategies were used. These strategies were giving rewards to hearers (3) and giving or asking for reasons (1). In these strategies, the reactor gave compliments and approval of the content reacted upon.

Indigo (pseudonym) cited lines from the vlog:

“'I would've like to see him use the other weapons like he had a lot to choose from.' 'I had fun watching it.", (MAED-05)

Second, there were eight utterances identified as bald on-record Politeness These utterances were manifested in the sub-strategies such as maximum efficiency (6) and giving task-oriented way of instruction (2). 
Alcosero, I. R., \& Gomez, D.

This strategy is characterized by direct and clear impositions. These were the statements during the analyses.

Towards the female marines, Yellow (pseudonym) firmly expressed:

"These women also are directly reacting to the video. The women also are not very particular on what might the viewers will say about them. They are trying to react directly without inhibition." (MAED-03)

Lily (pseudonym) also declared:

"The two female marines had been very honest and candid with their reactions. They expressed most of their agreements and disagreements in the video games directly, thus, using bald-on record politeness like when they say, 'Yeah, very, very, very unrealistic.'” (MAED-07)

Daisy (pseudonym) further explained:

"Bald on-record sa akoa because naay mga scenes didtoa nga unrealistic daw unya ana sila, 'What?'. They are direct to the point, they give criticism that most of the scenes there are unrealistic, not applicable in real life." (MAED-06)

(Bald on-record for me because there are scenes there that are unrealistic and they said, "What?". They are direct to the point, they give criticism that most of the scenes there are unrealistic, not applicable in real life.)

On the other hand, sharing her experiences on the impact of their reactions to herself and to the people behind the game, Green (pseudonym) justified:

"When it comes to obvious unrealistic scenes, the military personnel are not partial though "very unrealistic" which is fairly agreeable for hearers like me or it would not be treated as a threatening act, unless maybe if I am directly involve with the creation of the video game." (MAED-04)

Nonetheless, Daisy (pseudonym) concluded:

"Fictional lang jud ang game. Straight forward lang jud sila nga dili realistic ang game”. (MAED-06)

(The game is just fictional. They are just straight forward that the game is not realistic.)

Now, in terms of the other strategy giving task-oriented way of instructions, Indigo (pseudonym) cited:

"I guess it's bald on record politeness strategy because Jennifer shouted, "Come on bro, please wear your shirt”. (MAED-05)

Third, there were 22 utterances classified accordingly as off-record politeness. The frequency was distributed to the following sub-strategies: being ironic or using sarcasm (13), giving association clues (7), and using rhetorical questions (2). With the increasing number of indirectness and vagueness of utterances, the participants shared their contentions in the statements presented below.

Indigo (pseudonym) strongly asserted:

"The military personnel are professional soldiers but might not be professional reaction vloggers. They use a few off-record politeness and fewer positive politeness, a little superficial and more sarcastic. Compared to the priest who is covering a lot of considerations in making his imposition, the personnel are focus mainly on the game as a virtual platform only and almost disregards the makers of the game and the possible impact it may have in the market."

128 Consortia Academia Publishing (A partner of Network of Professional Researchers and Educators) 
(MAED-05)

Red (pseudonym) also admitted:

"They are reacting as if the game is a real simulation of a war. Not everything in the game is realistic - some are but others are not. I guess there are sarcasm in the end of the vloggers." (MAED-01)

When it came to the reactors non-verbal cues, Indigo (pseudonym) expressed concern and pointed:

“The speaker believed that it's not probable, that it is real. But the turning point of this all is the non-textual cue represented by a laugh. They laugh in this part, 'I love when everything tells you where ... superstore, train station. Haha.' The laugh, which strictly speaking might not be considered as an utterance, tip the whole politeness into sarcasm.” (MAED-05)

Similarly, Lily (pseudonym) conveyed:

“Carrying 100 pounds a gear is just so unrealistic, it's so funny.' By looking at their facial expressions, they expressed surprised and shocked looks. Also, especially to scenes when the player magically regenerate and magically get another life, just by merely mentioning the term 'magically' makes their reaction sarcastic” (MAED-07)

Green (pseudonym) also admitted:

"The reaction shows me the subtle effect of off-record politeness, to highlight points through mere description of the scene, without making the hearer or without giving the hearer enough ground to want to defend himself." (MAED-04)

Last, three utterances were categorized as negative Politeness. The frequency was distributed to the following sub-strategies: being pessimistic (2) and minimizing imposition (1). These were supported by the following statements during the analyses.

Towards the female marines, Daisy (pseudonym) explained:

"It is also being pessimistic in the line, 'I don't think that's how it works.'” (MAED-06)

In lessening the impact of imposition, Red (pseudonym) expressed:

“Jennifer said, 'The graphics are a little cheesy.' It's like saying. 'The graphics are not good.' It is quite polite in the conversation. You are not trying to criticize directly the one who made the video, but you are stating 'Oh, it's not good' but you are saying it in a rather lighter way." (MAED-01)

Overall, on the fact that the marine personnel used off-record politeness strategies, Green (pseudonym) firmly declared:

"Clearly unused to satisfying positive face wants. FTAs might be redressed to off-record politeness.” (MAED-04)

Indigo (pseudonym) strongly asserted:

"The military personnel are professional soldiers but might not be professional reaction vloggers" (MAED-05) 


\section{Table 7}

The summary of frequency and distribution of politeness strategies used in YouTube reaction vlogs

\begin{tabular}{|c|c|c|c|}
\hline No. & Politeness Strategies & Frequency & Percentage \\
\hline 1 & Positive Politeness & 111 & $48.05 \%$ \\
\hline 2 & Bald on-Record Politeness & 58 & $25.11 \%$ \\
\hline 3 & Off-Record Politeness & 32 & $13.85 \%$ \\
\hline 4 & Negative Politeness & 30 & $12.99 \%$ \\
\hline & Total & 231 & $100.00 \%$ \\
\hline
\end{tabular}

The frequency and distribution of politeness strategies in the five vlogs combined revealed that positive politeness was the dominantly used Politeness strategy (48.05\%), followed by bald on-record Politeness (25.11\%), off-record Politeness (13.85\%), and negative Politeness (12.99\%). Furthermore, there were five sub-strategies used in positive Politeness, three sub-strategies in bald on-record and off-record Politeness, and two sub-strategies in Negative politeness. Overall, there were a total of 231 utterances identified and classified by me and the seven participants during the careful analyses of the five reaction vlogs.

Positive Politeness - The commonly used politeness strategy was positive politeness garnering 111 out of 231 total utterances. Positive politeness was used to show solidarity between hearer and speaker through giving some positive value to the addressee. Specifically, the following positive politeness strategies were used: finding agreement (44), giving reward to hearers (37), giving or asking for reasons (21), avoidance of disagreement (7), and joking (2).

Firstly, finding agreement strategy reveals that the speaker saves the positive face of the hearer by finding ways to agree with the hearer. This is evident when the speaker indulged in safe topics and seeks possible topics where the speaker and hearer can decide and stick to the issues. In this study, the vloggers found ways to agree with the content they were reacting to and with the audience. Secondly, the giving rewards to hearers strategy depicts that the speaker satisfies the hearer's positive face by giving appreciation. This reward does not mean a form of material possession but by compliments, sympathy, and care. Here, the vloggers showed their admiration and commendation to the content they were giving reactions to. Thirdly, the giving or asking for reasons strategy shows that the speaker provides or asks reason about the hearer's wants to include the hearer in the activity. The goal is to assume cooperation from the hearer and to be viewed as cooperative. In the study, the reactors gave and asked reasons to explain and support specific points to show cooperation. Fourth, the avoidance of disagreement strategy depicts that the speaker is adhering to the hearer in the communication process to avoid disagreement. In this strategy, the speaker chooses to hide the dispute by agreeing with the hearer. In the context of reaction vlogs, the vloggers hint at disagreement with the topic but are careful enough not to offend the content creators and the audience. Lastly, joking is used to make the hearers feel at ease. Basically, jokes come from common thoughts, same background, and values. Particularly in this study, the reactors gave jokes knowing that the viewers share the same familiarity with what they were referring to.

As a whole, positive politeness strategies were utilized by reactors in their reaction vlogs to achieve the purpose of establishing common ground and solidarity with the creators of the content as well the audience/viewers. This was shown through appreciating the efforts of the creators as a reward for their hard work. The reactors also had been very careful in their words to satisfy the face wants of both the creators and the audience by avoiding disagreements by using positive comments and agreeing with the creators. Generally, the reactors had been very careful not to sound too imposing and rude with their imposition, so they used positive Politeness.

Bald on-Record Politeness - The second commonly used politeness strategy was bald on-record Politeness with 58 identified utterances out of 231. Bald on-record politeness refers to direct utterances used by speaker using clear statements. Specifically, the following bald on-record politeness strategies were used: giving warnings or sympathetic advice (29), maximum efficiency or being urgent and desperate (19) and giving task-oriented way of instruction (10). 
Firstly, giving warnings or sympathetic advice strategy depicts that the speaker cares about the hearer, maintaining the hearer's positive face. To carry out this purpose, expressing redress is not required since the goal of keeping the hearer from harm is of utmost priority. Thus, giving warnings to someone that could threaten him or comforting someone with advice is done. In the context of reaction vlogs, the reactors gave warnings and advice, especially to controversial and sensitive topics, with the aim of protecting them from harm and guiding them for future actions. Secondly, maximum efficiency strategy is used when efficiency is more important that saving hearer's face. This is evident when saving face is not a requirement. Thus, the utterance requires to be urgent and desperate because redressing tends to lessen the degree of urgency of the communication. Here, the expression of direct reactions and blunt words were expressed by reactors when giving their response. Lastly, giving task-oriented way of instruction strategy clearly asserts that face redress is unimportant. The focus of interaction is for the hearer to do something the speaker wants. This strategy can be done through giving a task, a command, or order. In the vlogs, this was prevalent when the reactors saw something incorrect and unapplicable in real life situation, and they tried to correct them by saying the things that should be done.

Bald on-record politeness strategies were used by the reactors to directly clear out the misinformation and negligence performed in the video contents. This made the utterances too imposing and direct, but the purpose of correcting was clearly addressed and grasped by the audience. This made bald on-record Politeness acceptable since the reactors were experts in the field and they had the authority to impose corrections and commands.

Off-Record Politeness - The third commonly used politeness strategy was off-record Politeness with 32 utterances out of 231. Off-record politeness refers to indirect utterances used to take some pressure off the speaker using vague manners that lead to more than one meaning to the hearer. Specifically, the following off-record politeness strategies were used: being ironic (32), giving association clues (13), and using rhetorical questions (10).

Firstly, being ironic strategy indicates that the speaker's remarks mean the opposite of what he seems to intend. Everything is up to the hearer to comprehend the meaning of the statement. In the vlogs, some of the reactors used sarcasm to perform this face threatening act. Secondly, giving associated clues strategy implies that the speaker states something that needs an action from the hearer. However, the speaker lets the hearer interpret the statement and leaves the responsibility of taking an action to them. In the vlogs, the reactors asked questions to make the hearers check their understanding without basically knowing their exact reaction in real life. Thus, the actions remain unclear since it could lead to more than one meaning to each hearer. Thirdly, using rhetorical questions strategy denotes that the speaker asks questions without expecting an answer from the hearer. A rhetorical question is a device used to subtly influence the hearers. Hence, it is asked not for an answer, but for effect. In this study, the reactors asked questions for the purpose of helping hearers to ponder on their thoughts and think deeper. Lastly, although verbal utterances were not exactly identified in the analyses, being ambiguous strategy was also evident in the sharing with the seven knowledgeable participants. This strategy implies that the speaker's statement is comprehendible and that there is more than one meaning to it. The ambiguity in the utterance makes the hearer to think what the speaker really meant, thus leaving the interpretation to the hearer. In the vlogs, the ambiguity of the vloggers' reactions was brought by the meaning explicit in their utterances and the message implied by their facial reactions.

Although some of the research participants doubted the appropriateness of off-record Politeness in reaction vlogs, their statements clearly proved that off-record Politeness is essential in this kind of computer-mediated communication. Particularly, since multiple meanings were conveyed in the utterances of the reactors, sometimes the danger of possible harsh criticism from the audience is prevalent when the result of the interpretation is not good. Despite this, the critical thinking ability of the viewers were nurtured since the interpretations are left to them.

Negative Politeness - The last commonly used politeness strategy is negative Politeness comprising 30 utterances out of 231. Negative politeness, also known as respect politeness, is used to ensure lesser possible 
Alcosero, I. R., \& Gomez, D.

offense that would occur in a communication. Specifically, the following negative politeness strategies were used: being pessimistic or expressing doubt (25) and minimizing the imposition (5).

Firstly, being pessimistic strategy implies that the speaker's wants is obtained by expressing doubt to avoid being too imposing to the hearer. The speaker maintains the hearer's negative face by giving the hearer freedom to act and decide on his own. This is done through using self-doubt phrases and giving suggestions instead of directly imposing the speaker's belief to the hearer. For the reactors, this strategy was manifested when they felt like the applicability of the concept was debatable, and their knowledge was limited and insufficient to defend the present contention. Moreover, minimizing the imposition strategy is manifested when the speaker does not want to impede the hearer's face by giving deference to the hearer. This is done when the speaker humbles himself and avoids forcing the hearers on his belief. This is marked by applying several words like a little, a bit, or a taste. In this study, the reactors tried to lower the impact of the possible offense that their imposition could cause to the hearers' face. Thus, negative politeness strategies were utilized by the vloggers through maintaining the freedom of the audience on what to do and believe in. They used strategies such as suggesting, humbling themselves, and using words to limit the impact of imposition as a sign of respect to the video content creators. Through this politeness strategy, the viewers got to decide on the validity of the vloggers' claims and the action that they would do.

Overall, the reactors/vloggers have used varying politeness strategies depending on the nature of the topics and the knowledge and experiences they hold. Positive Politeness was utilized since the vloggers opted to maintain solidarity and agreement with the creators and the audience/viewers. Bald on-record Politeness was also used to provide immediate feedback on details which could pose potential confusion and misinterpretation to the audience. On the other hand, off-record Politeness was employed by the vloggers to let the audience decide on their own and interpret the meaning of the vloggers' utterance without directly taking the whole responsibility of what they might think. Lastly, negative Politeness was applied to lessen the impact of the imposition made by the vloggers to protect and give respect to the video creators and to gain the respect of the viewers.

\subsection{Research Question No. 2. How do these politeness strategies in YouTube reaction vlogs influence viewers?}

To gather the detailed experiences, realizations, and insights of the research participants about how politeness strategies in reaction vlogs influenced them, the study employed phenomenological inquiry. In this second part of the research, there were 14 participants who were interviewed, seven for in-depth interviews and seven for focus group discussion. The participants shared their thoughts and ideas about how politeness strategies in the five YouTube reaction vlogs influenced them as critical individuals, as vlog enthusiasts, as educators, and as ordinary viewers. In this study, the results gathered revealed the following seven essential themes: make a good conversant, give respect and protect image, train how to evaluate issues and reactions, learn to appreciate vlogs, help control and manage reactions, develop to be a critical and analytical thinker, and aid in teaching-learning process.

Make a Good Conversant - A good conversant means being well-versed and well-informed in the purpose of communication and the means to achieve it. In the IDI, the participants shared that through politeness strategies, they can become mindful on what to say and how to say something. This makes it one of the advantages of using politeness strategies. Their responses are presented as follows.

Red (pseudonym) asserted:

"Being polite is interpreted as being a good conversationalist. You may want to bring up the point of contention but doesn't want to sound impolite, so you did it politely.” (IDI-01) 
Analysis of politeness strategies in Youtube reaction vlogs

Table 8

Essential themes and core ideas on How do these politeness strategies in YouTube reaction vlogs influence

viewers

\begin{tabular}{cc}
\hline Essential Themes & Core Ideas \\
\hline Make a good conversant & Being polite is interpreted as being a good conversationalist. You may want to bring up
\end{tabular}

Make a good conversant

Being polite is interpreted as being a good conversationalist. You may want to bring
the point of contention but doesn't want to sound impolite, so you did it politely.

Our moral conduct, as informed by religion and personal conscience, would champion politeness Therefore, politeness, as an act of reverence to the moral conduct has an inherent social and personal gratification. The social gratification includes many things like approval from contemporaries and lowers the defensive or hostility of the atmosphere. There is also a personal fulfilment in knowing you have followed proper conduct.

If you would like to use specific politeness strategy in reacting to a video, I think that you will be able to know the things you want to say and how you will say them.

Give respect and Politeness strategies lighten the emotional intensity created by confrontations of highly protect image sensitive topics. It would also satisfy positive/negative face wants and aims to maintain respect and professionalism in discussing matters that would normally threaten professionalism itself.

It may cover up or protect the person you are giving reaction. To protect your image also, you need to use positive reaction and use positive politeness.

If I were to react in this topic, I would use positive politeness for the programmers' effort and the detail of the game. I would use negative politeness in pointing out that it is hardly the "modern warfare" if they mean current for modern.

Train how to evaluate issues and reactions

These politeness strategies used in YouTube reactions vlogs gives us the freedom to evaluate the vlogger's way of speaking, his or her facial reactions, as well as the content itself.

Positive politeness noticed what is there but negative politeness would bring the hearer farther by pointing the wrongs in an acceptable utterance. We can't just stay with what is good as is highlighted by the positive politeness. We also need to unravel mistakes and imposed against it politely.

One must maintain a good balance between positive and negative politeness, with occasions of bald on record in case of violation on widely accepted do's and don'ts, with an exception to controversial topics which do's and don'ts are still being debated. Off record is also useful for points that will lead the hearer to something without directly planting it in his/her head. In that way, you won't be responsible for what he thought; quite typical for vloggers who must win the very fluctuating demands and sensitivity of the people.

Learn to appreciate vlogs

I like watching vlogs because they tell us about ourselves as well as represent a new form of self-expression, rooted in our today's communication environment.

It can give more idea and more learning for you especially if you are trying to learn the truthfulness in videos presented and what are the experts reaction to it. Hearing the experts, it may give you knowledge on things which are true on their field and maybe exaggerations on the videos they are giving reaction.

The politeness in this vlog influenced my sense of sympathy and understanding of the person in question.

Help control and

manage reactions

The advantages of using politeness strategies in reaction vlogs in different context are freedom of mixing politeness strategies in a single setting and an effort to prevent or repair damages caused by the facial reactions by the speaker. One can actually remodify the conversation to less threatening.

There should be politeness strategies to limit the words and reactions of the vloggers. It will guide them on the scope of criticism they should give.

Its usage depends on the situation or video you are reacting on and level of understanding in a certain topic. If you do not have enough knowledge and expertise on certain content, negative politeness should be used.

Develop to be a critical and analytical thinker

I think I would also use bald on record and positive politeness more often. The audience need an expert advice and I believe it would be helpful if I would put direct and absolute confidence in my medical advice through bald on record. Positive politeness is undoubtedly needed too. Nonetheless, I think I would not exaggerate my bald on record politeness as to shout and saying it once might be enough.

Generally, I would not give exaggerated reaction if I do not know the whole story.

I would also prefer to just avoid the topic, if not, in reverence to my own bias, would not probably maintain face-satisfying acts.

Aid in teaching-learning process

Reaction vlogs are good springboard in teaching politeness theory and pragmatics. They are a good source to have in teaching communication in context.

Reaction vlogs model the authentic use of politeness utterances which structure could 
be a useful input in learning English with the consolation of good values.

The higher order thinking skills (HOTS) of the students are developed when they analyzed vlogger's reactions and when they are tasked to give their own reaction to specific issue or content.

Green (pseudonym) added:

"Our moral conduct, as informed by religion and personal conscience, would champion politeness Therefore, politeness, as an act of reverence to the moral conduct has an inherent social and personal gratification. The social gratification includes many things like approval from contemporaries and lowers the defensive or hostility of the atmosphere. There is also a personal fulfilment in knowing you have followed proper conduct." (IDI-05)

Yellow (pseudonym) expressed:

"If you would like to use specific politeness strategy in reacting to a video, I think that you will be able to know the things you want to say and how you will say them. If your main purpose is to give reactions that would interest the viewers, you can use positive politeness even if you are not really agreeing or disagreeing to that video. But if you want to be honest and be direct, you can use bald on record." (IDI-03)

Indigo (pseudonym) imparted:

"Instead of being impolite to unrealistic scene I might use negative politeness. For instance, instead of saying, 'Are you crazy?' I might say 'There must be a reasonable cause behind this action but in my opinion, I do not think it is very kind to do that." "(IDI-06)

Violet (pseudonym) declared:

"Positive politeness strategy is very effective when it comes to conversation because you are not only speaking on behalf of your brain but also on behalf of whom you are speaking with. I guess, when you learn to speak with people and through people, the right facial reactions will follow, and you are gaining an improvement to yourself." (IDI-07)

The abovementioned responses intensify the idea that being polite equates to being a good communicator. The knowledge of politeness strategies gives them freedom and flexibility in the conversation since the participants realized that one varies reactions depending on a particular context. This means that since conversation differ from time to time and from people to people, the speakers have the upper hand to decide on what strategy to use, which he thinks appropriate or inappropriate in a certain situation. Nonetheless, it is stressed that there is no harm in being polite in a conversation.

Give Respect and Protect Image - With varying opinions and standards, one reaction could give a diverse degree of impact on a person's intellect and emotion. Thus, one needs to exercise caution to maintain one's reputation. With this, the participants stressed the importance of using politeness strategy to protect the image of the individuals and theirs. Below are their answers in the IDI and FGD.

Green (pseudonym) explained:

"Politeness strategies lighten the emotional intensity created by confrontations of highly sensitive topics. The vlog with the priest is a great example. The jokes made a break after a series of FTAs he is trying his best to redress. The positive politeness at least, in desperation, seems to make up the impositions. It would also satisfy positive/negative face wants and aims to maintain respect and professionalism in discussing matters that would normally threaten professionalism itself." (IDI-04)

134 Consortia Academia Publishing (A partner of Network of Professional Researchers and Educators) 
Lily (pseudonym) also described:

"It may cover up or protect the person you are giving reaction. For example, the priest is using politeness strategies to protect the image of the singer. To protect your image also, you need to use positive reaction and use positive politeness because we all know that Ariana Grande, is very much popular and influential.” (FGD-07)

When given a chance to react to the video game, Indigo (pseudonym) said:

"If I were to react in this topic, I would use positive politeness for the programmers' effort and the detail of the game. I would use negative politeness in pointing out that it is hardly the "modern warfare" if they mean current for modern." (IDI-06)

To react to a controversial song relating to God, Blue (pseudonym) firmly asserted:

"Same with what the priest did, I guess I will be friendly and also jolly in reacting because I do not want that Ariana Grande will be mad at me." (IDI-05)

From their responses, it could be deduced that politeness strategies in reaction vlogs could either protect or attack one's image. Especially when controversial topics are discussed, there are times when people get too much involved that they become rude and impolite with their reactions. Fortunately, based on the sharing of the participants, they advocate giving respect at all costs to the individuals in question especially if they are influential or the nature of topic is sensitive. For them, showing respect and protecting the image of the persons involved in the reaction vlogs resonates with protecting their image also.

Train How to Evaluate Issues and Reactions - Based on the politeness strategy used by the vloggers, the participants have formed some impressions about who is a better reactor and who is not. Also, they have realized the varying functions of the four politeness strategies in reaction vlogs. As such, they can relate these impressions and roles to their judgment especially when they put themselves on the shoes of the vloggers. Their responses are recorded as follows.

Violet (pseudonym) said:

"These politeness strategies used in YouTube reactions vlogs gives us the freedom to evaluate the vlogger's way of speaking, his or her facial reactions, as well as the content itself." (IDI-07)

Indigo (pseudonym) added:

"Positive politeness noticed what is there, but negative politeness would bring the hearer farther by pointing the wrongs in an acceptable utterance. We can't just stay with what is good as is highlighted by the positive politeness. We also need to unravel mistakes and impose against it politely." (IDI-06)

Green (pseudonym) affirmed:

"One must maintain a good balance between positive and negative politeness, with occasions of bald on record in case of violation on widely accepted do's and don'ts, with an exception to controversial topics which do's and don'ts are still being debated. Off record is also useful for points that will lead the hearer to something without directly planting it in his/her head. In that way, you won't be responsible for what he thought; quite typical for vloggers who must win the very fluctuating demands and sensitivity of the people." (IDI-04)

Green (pseudonym) asserted:

"Medical topics are complicated for me as it is outside my profession. If I were to react on such 
topics, unlike the doctor who rarely use negative politeness, I would probably be politer. Though to him it is fairly reasonable to use bare FTAs, I would probably use more redresses and would even do away with bald on record as it would be too imposing for a non-expert. I would be genuine with my positive politeness, just as what medical procedures deserve." (IDI-04)

The participants stressed the importance of each politeness strategy when giving reactions. According to them, positive politeness is suitable when the reactor is a non-expert in a particular topic; bald on-record politeness is needed when pinpointing inappropriate information and correcting them; negative politeness is advised when giving respect to the effort exerted in the performance of a task; and off-record politeness is effective when avoiding the responsibility of what the hearers will think. With these realizations, whichever topic is present, the participants could become a flexible and fair reactor.

Learn to Appreciate Vlogs - There are different types of vlogs on YouTube that the participants are generally indulged into. However, in this study, they are immersed in reaction vlogs. Vlogging, as a new form of self-expression, made them appreciate the factual information they get from the content of the reaction vlogs and admire the techniques used by vloggers in presenting their claims. These are evident in the statements of the participants during the IDI and FGD below.

Violet (pseudonym) uttered:

"I like watching vlogs because they tell us about ourselves as well as represent a new form of self-expression, rooted in our today's communication environment." (IDI-07)

Lily (pseudonym) exclaimed:

"It can give more idea and more learning for you especially if you are trying to learn the truthfulness in videos presented and what are the experts reaction to it. Hearing the experts, it may give you knowledge on things which are true on their field and maybe exaggerations on the videos they are giving reaction." (FGD-07)

Green (pseudonym) affirmed:

"The politeness in this vlog influenced my sense of sympathy and understanding of the person in question." (IDI-04)

The abovementioned statements of the participants showed their appreciation to the characteristic of reaction vlogs and methods used by the vloggers in conveying their ideas. Reaction vlogs reveal the truthfulness of content since the information directly came from the experts who practice and experience them hence, the audience could reflect on what is real and not. On the other hand, the participants admire how the vloggers showed fairness in giving their criticisms and admirations and honesty in telling the audience of the limitation of their knowledge.

Help Control and Manage Reactions - The first thing the audience usually notices in a reaction vlog is the facial reactions of the vloggers. If one will rely only on the facial expressions of the vloggers, there could be a misinterpretation of one's perception of the vloggers' personality and attitude towards the topic. To remediate this emerging discrepancy, politeness strategies played a relevant role. Its role is discussed in the IDI and FGD presented below.

Orange (pseudonym) added:

"Its usage depends on the situation or video you are reacting on and level of understanding in a certain topic. If you do not have enough knowledge and expertise on certain content, negative politeness should be used." (IDI-02) 
Daisy (pseudonym) affirmed:

"Yes, dapat naay politeness strategies to limit their words, their reactions, advantage siya sa vloggers para guided sila sa scope sa ilang pag-criticize.” (FGD-01)

(Yes, there should be politeness strategies to limit the words and reactions of the vloggers. It will guide them on the scope of criticism they should give.)

Indigo (pseudonym) expressed:

"The awareness of it would be helpful in giving reactions especially to sensitive topics that he/she would not surely want to be misinterpreted as acting with total polemic and indifferent. Politeness strategies also act as filters in expressing opinions in a way that is most acceptable or tolerable to the hearer." (IDI-06)

Violet (pseudonym) also stated:

"I have understood that if our facial reactions would mean negative, in this case, can be prevented or repaired using different politeness strategies and can largely affect the conversation and the people that surrounds us even in real life setting." (IDI-07)

The above contention of the participants stressed the importance of politeness strategies to repair the negative connotation of facial reactions that sometimes directly influence the audience. It is not always that one will rely on what is seen but must also learn to listen. Thus, the participants highlighted using politeness strategies to create a balance between facial reactions and verbal reactions.

Develop to be a Critical and Analytical Thinker - Giving the proper reaction to a particular topic is hard to attain especially when the dos and don'ts is still debatable. As such, it is essential to think very carefully before voicing opinions. Hence, while trying to weigh the appropriate politeness strategy to use in reaction vlog, the participants derived to the understanding that they should be selective on the politeness strategies to use, firm in defending their claim, and well-informed with the pros and cons of their imposition. These are conveyed in the following statements.

Indigo (pseudonym) uttered:

"I think I would also use bald on record and positive politeness more often. The audience need an expert advice and I believe it would be helpful if I would put direct and absolute confidence in my medical advice through bald on record. Positive politeness is undoubtedly needed too. Nonetheless, I think I would not exaggerate my bald on record politeness as to shout, 'Put on the mask, Shaun!' or 'Don't take it out!' and saying it once might be enough. I think the tone of my voice which might be non-textual cue would reinforce my intended politeness." (IDI-06)

Orange (pseudonym) exclaimed:

"Generally, dili ko maghatag og exaggerated nga reaction if in my side wala ko kabalo sa whole story. In this case sa Iron Man nga movie, kung unsa lang jud ang na-present, react-kan nako siya but not in a way nga pa-hawd-hawd ko ani nga pag-react.” (IDI-02)

(Generally, I would not give exaggerated reaction if in my side I do not know the whole story. In the case of Iron Man movie, if what is presented, I would react to it but not in a way that it is a very expert reaction.)

Indigo (pseudonym) affirmed:

"I would employ as much politeness strategies as I could. I cannot be rude. History tells us how 
self-righteousness brought about the destruction that the same faith promises to eradicate. However, I would bring my own biases, too, as I don't want to validate Ariana's audacity of comparing herself, or what she thinks she represent, to things which most people closely tie to the image of God." (IDI-06)

Green (pseudonym) explained:

“The priest's confessed apprehension influences me to be highly critical and polite with theological topics especially if the human in question is an influencer or in a highly respected position or representative of a certain population/belief. I would also prefer to just avoid the topic, if not, in reverence to my own bias, would not probably maintain face-satisfying acts." (IDI-04)

Red (pseudonym) claimed:

"What you say is as important as how you say it. It is our duty therefore to be sensitive in our words so as not to offend audience or the one who created the movie or the vlog. But I still am to saying blunt words if needed to others only if we have known each other so well to be efficient in communication." (IDI-01)

In the above statements, the participants have varying styles and reasons on what strategy to use in certain subject. Some of them liked to face the topic fiercely through blunt words and lightly through a caring tone. However, there is one who will just avoid the subject, especially if its controversial. Whichever it may be, they all agreed that one should be aware of the consequences of their reactions and opinions.

Aid in Teaching-Learning Process - Since all the participants are educators, they discussed how politeness strategies in reaction vlogs could contribute to the teaching-learning process. They agreed that reaction vlogs could be used to teach the concept of politeness strategies in pragmatics, the values of being polite, and other relevant skills the learners could use. Below are the detailed responses in the IDI and FGD.

Red (pseudonym) asserted:

"Reaction vlogs are good springboard in teaching politeness theory and pragmatics. They are a good source to have in teaching communication in context. In a way, it will help me in teaching-learning process because reaction vlogs are good springboards." (IDI-01)

Indigo (pseudonym) expressed:

"Students could also learn language from vlogs. Reaction vlogs model the authentic use of politeness utterances which structure could be a useful input in learning English with the consolation of good values." (IDI-06)

Orchid (pseudonym) added:

“Ma-develop ang HOTS (higher order thinking skills) sa students kay mag-analyze man sila." (FGD-06)

"It could develop the higher order thinking skills (HOTS) of the students because they will analyze."

Yellow (pseudonym) imparted:

"Reaction vlogs can be used in teaching-learning process through teaching the students on how they can express their opinions and ideas with the use of politeness strategies.” (IDI-03) 
Blue (pseudonym) declared:

"In the classroom context, teachers could learn strategies on approaching sensitive themes. Students can be vulnerable to offense and quick to cherish praise. Politeness could minimize potential offense that might cause damage on the student's social and self-mage. Since most students nowadays are more on social media, it is fitting that teachers utilize/integrate vlogs in presenting lessons by showing it to the class and let the students watch and learn from it." (IDI-04)

The abovementioned contention of the participants had somehow attained one of this study's objectives, that is, to introduce readily available and easily accessed resources that could potentially help in the teaching-learning process. If used, the selection of reaction vlog content will be put in the teachers' hand and that they should be meticulous in choosing the vlogs that are applicable in the classroom context. Therefore, reaction vlogs, as an investigative genre of vlogging, could help teach students analytical and critical thinking skills with the integration of good values.

Overall, the participants have cited the helpful benefits of politeness strategies in YouTube reactions vlogs. Throughout this study, the participants realized that using politeness strategies in reaction vlogs makes one a good conversant and critical and analytical thinker since one will know what to say and how to say their reactions. Also, its usage fosters giving respect and protecting image of both the individuals who exerted effort in developing the content as well as the reactors or vloggers who voiced out their judgment and opinions. Furthermore, the knowledge on the role of each politeness strategy helps train one how to evaluate issues and reactions and help control and manage reactions. Finally, as reaction vlogs offer authentic use of language and politeness strategies serve as a guide to tolerable conduct, the participants learn to appreciate vlogs and enumerate ways on how it could be used to aid in teaching-learning process.

\section{Discussions}

Politeness Strategies used in YouTube Reaction Vlogs. In analyzing the politeness strategies used in the vlogs, the seven MAED participants and I categorized the analyses and interpretation into four, namely, positive politeness, bald on-record, off-record politeness, and negative politeness. The verbal reactions of the vloggers were interpreted by citing lines and phrases they uttered and considering the non-verbal responses like facial expressions, gestures, posture, tone, pitch, and volume. Hereto, in the corpora of reaction vlogs in this research, the reactors/vloggers were considered the speakers $(\mathrm{S})$ and the hearers $(\mathrm{H})$ were the viewers/audience (H1), and the video content creators $(\mathrm{H} 2)$ of the song, movies, drama, and online game reacted upon. With these personalities, the discussion of the results garnered from the interviews were analyzed according to $\mathrm{S}$ to $\mathrm{H} 1$ and $\mathrm{S}$ to $\mathrm{H} 2$ interaction to provide an individualistic approach in realizing the politeness strategies used.

Based on the researcher's analyses and seven participants, the reactors have used positive politeness strategies in reacting to the video contents. They showed appreciation and agreement on the content they were reacting with through using the positive politeness sub-strategies such as finding agreement in the form of conformity and approval, giving rewards to hearer in a form of compliments, sympathy, and care, giving or asking for reasons as a sign of being cooperative and supportive, avoidance of disagreement through sense of understanding, and joking to add humor in their utterances. Generally, the participants pointed out that the friendly, welcoming, and approachable personalities to the ideas presented in the video contents would encourage more viewers' subscriptions.

The reactors showed appreciation to the content creators' effort and hard work and considered the viewers' feelings when their favorite artist, game, or movie were commented on. To realize this, the reactors have used positive politeness strategies. This result parallels the study of Brown (2015) stating that expressions of approval and care depicted in the reactors' utterances helped achieve social closeness with the content creators and the audience themselves. Furthermore, the reactors commended how the concepts were strategically presented, the 
beautifully put together rhythm, and how the content creators flawlessly executed the procedures These were evident in the lines like, "It's a good advice, that's impressive.", "I like the song. I like the beat.", and "That's actually accurate.". The reactors reached the audience, who were then encouraged to watch their vlogs by saying these positive comments. Through giving compliments, the reactors established rapport and common ground with the content creators and audience. Like the study of Al-Azzawi (2011), compliments and praise give credit and positive value to the hearer's face. People usually compliment someone's appearance, ability, possessions, personality, and other characteristics.

Moreover, the participants pointed out the vloggers' involvement in the video content through giving sympathy. To validate the truthfulness of the content, the reactors said, "That happens to me", "We do that every day with our cook", and "I did that every day.". Through their declaration of indirect involvement, they were able to shorten the social distance between them and the hearers like the study of Jiang (2010). Through this, they were able to send a message that the content was true and believable. In doing this, the reactors have established connection or closeness with the creators and the viewers. More so, through agreeing and conforming, the hearers' positive faces were saved. In the lines, "I agree" and "I agree with the president.", the reactors approved the video content. The finding agreement sub-strategy was employed where the vloggers found ways to agree with the content creators. In this way, the positive face was maintained or the wants to be approved by others (Brown \& Levinson, 1987). On the part of the viewers, the reactors' conformity and approval signified the truthfulness and validity of content that the viewers would likely accept because it came from the experts in the field.

Along with giving sympathy, like the study of Monsefi and Hadidi (2015), another result shows that a sense of understanding to a certain circumstance helps protect an individual's image For instance, in the line "But I understand that they need that factor to make the show work.", the reactor (doctor) preferred to understand the situation instead of saying that the content was unrealistic. Another, the participants pointed out the priest showed open-mindedness when he put into consideration the idea that God is a woman instead of immediately concluding that it was untrue in line "I think that is probably a true statement.". Hence, the vloggers have critically emphasized where the idea came from and seemingly defended the creators. This closely pertains to the sub-strategies finding agreement and avoidance of disagreement of Brown and Levinson (1987). Instead of showing their discord in the reaction vlogs, they hid their disagreements not to offend the creators and the viewers.

Other utterances in the vlogs that exemplified the sub-strategy avoidance of disagreement were the use of token agreement (Brown \& Levinson, 1987). Token agreement is characterized by saying approval of something and followed by a statement of disagreement. For instance, the reactor (doctor) said "I like him cause he's superhuman and knows everything but it's just so unrealistic.". The "I like... but..." structure was also used by the reactor (priest) in the line, "Oh my dear, I really like the beat, but I'm not sure about the lyrics.". Secondly, the reactors have used bald on-record politeness strategies through using direct and straightforward utterances with the aim of relaying clear statements about the truthfulness of the content they were reacting. Dominant bald on-record politeness sub-strategies used include giving warnings or sympathetic advice, maximum efficiency (being urgent and desperate), and giving task-oriented way of instruction. Here, the reactors/vloggers' usage of bald on-record politeness was necessary to protect the viewers from the burden of inaccuracy and misinformation. Moreover, this implied that the participants understood the reactors' direct feedback and immediate reactions since they could be held accountable also for introducing correction and new information to the viewers.

When the speaker truly cares, they make sure that no harm would be inflicted on the hearers. To attain this, the giving of warning or sympathetic advice is used (Brown \& Levinson, 1987). In the reactor's utterance (priest), he expressed concern on the welfare of the singer through saying the lines, "So yeah, Ariana. Better check yourself before you wreck yourself." and "Yeah, she's misquoting scripture which is actually quite dangerous because it does say at the end of the Bible, don't misquote it.". Here, the reactor attempted to take away the 
content creator's freedom to act based on her own belief; instead he gave clear warnings to save the hearer from harm. Similar to the study of Rohali (2019), through giving warning, as a form of direct utterance, the hearer would be notified immediately on what to do to avoid potential harm. Another, in the lines, "You need to be a lot more careful cause this isn't just a game, it's people's life at risk.", the reactor (doctor) firmly stressed the importance of caution in medical procedures through warning that it was not a game but a serious matter.

Next, maximum efficiency (being urgent and desperate) sub-strategy is used when efficiency and urgency is more important than saving the hearer's face (Brown \& Levinson, 1987). Based on the analyses, the female marines were the obvious reactors who used this strategy. Accordingly, they expressed their reactions, which were mostly disagreements, directly without any inhibition or care about the game developers and viewers. For instance, in the lines, "Yeah, very, very, very unrealistic." and "It's gonna be really cumbersome and running with that kind of gear is just unrealistic", they clearly stated that the scenes were too good to be true. Also, the reactor (doctor) bluntly said, "That's not the right way to do it." and "That's not perfect.". Here, the reactors emphasized the importance of their direct utterances, mainly to give corrections, without trying to please the creators and viewers' faces. Parallel to the study of Putri (2013), the speaker tends to perform at maximum efficiency to convey the needed information by employing less redressive utterances to the hearer's face.

Thirdly, giving task-oriented instruction means that the speaker wants the hearer to do something (Brown \& Levinson, 1987). These are evident in the lines, "Put your mask on”, "Don't take it out", "You need to...", and "You should be...". On the reactor (doctor) part, he said those lines in a rush manner while shouting and repeating the lines. His reactions threatened the hearers' freedom of action. This result parallels the study conducted by Febtrina (2019) that states that bald on-record politeness was usually manifested when the speaker is in a rush or state of emergency. In the same way, the reactor had raised his voice and repeated the sentences to clearly state that something must be done clearly.

From the above strategies and examples, it could be deduced that the reactors mainly employed bald-on record politeness to correct inaccurate information in the video contents. In this case, the vloggers/reactors had the power to give feedback and corrections because of two factors - expertise in the topics and ownership of the YouTube channel. This result closely pertains to the notion of Culpeper (1996) that bald on-record politeness is applicable when the threat to the hearer's face is minimal or in a situation when the speaker is more powerful than the hearer. As social media influencers, they could be held accountable for the corrections and new information they shared. Thus, their direct utterances were employed not only to impose their wants and needs to the hearers but also to disseminate accurate information for the sake of the viewers. With this reason, based on the participants' sharing, they understood the need for immediate and direct response. In relation to the threat to the hearer's face, this result supports Brown (2015) that just like positive politeness, the danger incurred by the FTAs in bald on-record politeness is low.

However, since YouTube is a public site, the content of their reaction could also make viewers formulate judgments about them and their entire profession. Thus, one must be careful in uploading contents in public sites. For example, one of the research participants said, "The military personnel are professional soldiers but might not be professional reaction vloggers... I guess in the training they are shouting with each other.". This contention confirms the result of the study conducted by Greysen, Kind, and Chretien (2010) that their comments affected their status as vloggers/reactors and their profession in general.

Results of this study further showed that off record politeness strategies were used by reactors manifested in the sub-strategies being ironic, giving association clues, and using rhetorical questions. Basically, off-record politeness is used by a speaker to deliver indirect utterances to the hearers and let them interpret its meaning without acknowledging the responsibility or blame to them alone. Thus, the meaning of the reactors' utterances was not made clear because they wanted the viewers to make their interpretation. According to the participants' sharing, in reaction vlogs, off-record politeness must be least used because it may lead to viewers' misleading interpretation. Nonetheless, they expressed that off-record politeness is essential since it promotes curiosity and 
critical thinking skills, inciting thought-provoking discussions amongst viewers.

First off, the analyses pointed out that the reactors were being ironic when their utterance means the opposite of what they seemed to intend. This was evident by using sarcasm. Pertaining to the reactors (female marines), the participants observed, "But the turning point of this all is the non-textual cue represented by a laugh...The laugh, which strictly speaking might not be considered as an utterance, tip the whole politeness into sarcasm." When solely examined, their words would suggest that they agreed on the events of the games. However, when they laughed after commenting and comparing, the participants assumed that they did not mean what they first said. These observations were supported by Gibbs (2000) as cited by Prokofiev (2017). Accordingly, laugh and monotonous intonation are two of prosodic markers of ironic and sarcastic utterances.

In connection to this, it is important to note that the participants detected sarcasm on reactors' utterances when they watched the vlogs and saw their non-verbal cues. Similarly, majority of the participants noticed that ambiguity was prevalent in the non-verbal cues of the reactors. In the observation, "The priest is trying to use facial expressions like smirking, trying to make his eyes wider, so I felt like his words are somehow different from his facial expressions.". Therefore, the meaning conveyed from what the reactors said was different from what was implied in their facial reactions. Evidently, the participants found it hard to read the meaning of the reactors' facial reactions when they tried to make sense of the words that came out from their mouth simultaneously. This result supports the study conducted by Hassin, Aviezer, and Bentin (2013) revealing that facial expressions of emotions are inherently ambiguous, and reading them is never an easy task.

Another, in one of their observations, "I don't actually see it on his face, but on his voice.". Here, aside from the ambiguity that facial reactions brought, the tone of the voice made their utterances ambiguous. This result supports the study of Yanti (2017). Accordingly, off-record politeness depends on the context of a situation, degree of assertion, and speaker's intonation. In the same way, the results of this study confirmed that one's tone triggered indirectness in utterance. Therefore, in the analyses, the participants instantly perceived the reactors as ironic and ambiguous because of their non-verbal cues such as facial expressions, tone, and voice.

Furthermore, in contrast to giving task-oriented way of instruction in bald on-politeness, giving association clues in off-record politeness means wanting something to be done through implied and indirect utterances. In most reaction vlogs, the reactors wanted the viewers to think deeper and investigate more. For instance, the reactor (priest) said, "If anyone knows, please explain.". In the line, the reactor wanted the viewers to analyze and investigate more to explain and clarify something. In addition, the reactor (doctor) said, "How about getting him to sign all the paper works and disclosures and hippo forms and making sure he has identification?". The reactor indirectly told viewers that documentation was the basic procedure that must be done when performing medical operations. These findings were like the study of Putri (2013) in which giving association clues could be done through series of questioning. The interrogative forms make the utterances more indirect and safer from criticism compared to declarative forms that make one's motive obvious.

In connection to this, a series of questioning does not only mean wanting something to be done as implied by giving association clues strategy. Series of questioning could also be used to influence and convince hearers of the imposition. This is done through the sub-strategy using rhetorical questions (Brown \& Levinson, 1987). For instance, in the lines of the reactors (female marines), "Like can you imagine if they were real?" or to the reactor (doctor), "Is this the same security guard who knows everywhere he's gonna go? Maybe this guy is a savant too?", the reactors asked questions not mainly to get answers but also to influence the viewers of the interpretation that they have.

Lastly, negative politeness strategies were used to lessen the impact of the reactors' imposition against the viewers' freedom of action and thought. This was evident in the negative politeness sub-strategies such as being pessimistic (expressing doubt) and minimizing the imposition. The research participants thought that the reactors' contradictions to some questionable segments of the video contents were acceptable. However, in doing so, they realized that the reactors did not wish to force their beliefs on the viewers. Instead, they showed respect and 
humility towards the ideas of the video creators and the feelings of the viewers.

Based on the participants' sharing, the reactor (engineer) mostly used pessimism in his reaction vlog as his way of responding to the accuracy of the presented information instead of imposing his wants. Negative politeness was prevalent in self-doubt phrases like "I'm not actually sure..., I don't understand how, I just know." when he could mean "That's wrong/false.". In the study of Putri (2013), the subject of their study employed pessimism by expressing doubt about the situation but seemed amazed and awed at the same time. Similarly, in this study, the reactor (engineer) expressed doubt on the accuracy of the technology used in Iron Man movie with respect to the real and current trend in science and engineering, but at the same time astonished about how it worked. Moreover, it is important to note that the reactor's astonishment and wonder may be influenced by the factor that he was a fan of Iron Man as he disclosed it at the beginning of his vlog. Moreover, the vlogger (priest) uttered the lines, "I'm not saying I'm a font of all knowledge... I don't know it off by heart." to express doubt. Based on the participants, the priest needed it most to use negative politeness compared to other vlogs because of how sensitive and controversial the topic was. With this, the reactor put greater effort in using redressive utterances to protect his image as priest and the religion he represents, the image of Ariana Grande and the creators, and the opinion of the viewers towards him and the singer. According to Brown (2015), when there is a higher level of threat that an utterance can cause, it is vital to use negative politeness compared to the other two strategies like positive and bald on-record politeness. As such, in this study, the priest was able to maintain the hearers' negative face through using self-effacement, formality, and restraint.

Also, based on the participants' sharing, although there were negative statements on the priest' contradictions from what he sees and believes, he expressed them nicely to avoid getting negative reactions from the viewers. Like the study of Chikwaya and Zhang (2018), viewers and subscribers play an important role in vlogging culture. Their approval and content preferences are the vloggers guide for future content. Similarly, in this research, the priest, have considered what the viewers might feel with his imposition, especially that the topic was controversial, to encourage more viewership.

Next, minimizing the imposition refers to the speaker's strategy of lessening the impact of the imposition through giving deference to the hearers and applying several words like a little, a bit, or a taste. This is done when the speaker humbles himself and avoids forcing his belief on the hearer (Brown \& Levinson, 1987). For instance, instead of directly saying "This is unrealistic", the reactors (chefs) said, "This was almost unrealistic for movie scene...Well, that was a little dramatic". The use of "almost" and "little" depicts that the chefs tried to minimize the imposition by using words to lessen the impact or intensity. Thus, the reactors showed respect to the creators by using lesser offensive utterances instead of being too imposing with their beliefs. Like the study of Dharmayanti, Sukarini, and Savitri (2018), interlocutors tend to minimize impositions through using words that would not insult each other but help protect each other's face.

Overall, in this study, the reactors/vloggers have used varying politeness strategies depending on the nature of the topics and the knowledge and experiences they hold. Positive politeness was employed through conforming and giving appreciation to maintain solidarity and social closeness with the creators and the audience/viewers. Bald on-record politeness was also used to provide immediate feedback on debatable and questionable segments of the contents to verify their truthfulness and to provide more accurate information to the audience. On the other hand, off-record politeness was applied by the reactors to indirectly plant ideas on the viewers' head to make them do something and think deeper. Lastly, negative politeness was used to protect and give respect to the video creators and gain the respect of the viewers.

Interpretation of the Audience on the Influence of Politeness Strategies in YouTube Reaction Vlogs. To gather the detailed experiences and realizations of the participants about how politeness strategies in reaction vlogs influenced them, the study employed phenomenological inquiry. The participants shared their thoughts and ideas about how politeness in reaction vlogs may influence ordinary viewers. They expressed their opinions, experiences, and realizations as they took the roles of critical individuals, vlog enthusiasts, educators, and 
ordinary viewers. Based on the data gathered from the interviews, the seven essential themes came out: make a good conversant, give respect and protect image, train how to evaluate issues and reactions, learn to appreciate vlogs, help control and manage reactions, develop to be a critical and analytical thinker, and aid in teaching-learning process.

Firstly, the participants realized that using politeness strategies in reaction vlogs makes one a good conversant. Being a good conversant means being well-versed and well-informed in the purpose of communication and the means to achieve it. Based on the results of this study, the participants realized that one could be mindful on what to say and how to say it because of politeness strategies. According to the participants' sharing, "Being polite is interpreted as being a good conversationalist.". This statement reflects the general view of politeness that is embraced by the public. However, there are different standard for one to be considered a good conversationalist. As studied by Fraser (1990), social-norm view of politeness lies on a conversationalist' conformity and non-conformity to societal norms; Grice conversational maxim looks at a good conversationalists as rational individuals capable of conveying messages efficiently; and Brown and Levinson's perceives politeness as an effort of satisfying the hearer's face. With these views, it could be deduced that the participant's realization about this study is similar with that of the classic researchers of politeness.

In addition, it was said, "Politeness, as an act of reverence to the moral conduct has an inherent social and personal gratification.". Compared to the three views presented above, if politeness is treated as moral conduct, people's act of politeness would revolve on personal conscience, the notion of right and wrong, justice, and decency. According to Brown (2015), with this viewpoint of politeness, how it is linguistically and socially measured is challenging to determine. It is harder to explore on moral factors affecting one's politeness. Thus, Brown suggested that investigating social factors such as language, people's characteristics, and social context would be more possible. For instance, in terms of language use, using politeness strategies makes utterance lengthier and wordier. The participants shared, if negative politeness is used, 'Instead of saying "Are you crazy?"', I might say "There must be a reasonable cause behind this action, but in my opinion, I do not think it is very kind to do that." In this utterance, the impact of the blunt form of the shorter version was minimized by the longer version making one a good conversationalist. This result supports the claim of Leech (2014) postulating that increasing politeness equates to wordiness.

Furthermore, according to Kim (2017), people say what they need to say because of five different motives: to avoid hurting hearer's feelings, to minimize imposition, to avoid negative evaluation by hearer, to ensure clarity, and effectiveness. Given these factors, whichever is put first, affects the conversational strategies and tactic employed by a speaker. As one of the research participants pointed, "If you would like to use specific politeness strategy in reacting to a video, I think that you will be able to know the things you want to say and how you will say them", Hence, in relation to the study at hand, when one's motive was decided, the appropriate politeness strategies and right reactions would come naturally. For instance, a balance between positive and negative politeness was employed in the speech of Tony Abbot (Handoko, 2014) and Barack Obama (Sari, 2016). This means that the speakers were conscious on the function of communication; thus, they knew that a single politeness strategy used in the whole duration of their speech would be ineffective and less appealing to the audience. Similarly, in this study, the participants stressed that by knowing the politeness strategies, one can understand the things to say and how to tell them based on the context of communication.

Secondly, by being mindful of what and how to express reactions, politeness strategies helped give respect and protect people's image in each communication context. Especially if the people involved are influential and the topics in question are controversial, giving respect and protecting their image resonates to protecting the speaker's own image also. As Greysen, Kind, and Chretien (2010) stressed, public comments posted by professionals in social media do not only affect that one person who posted but the entirety of profession. Thus, it is vital to be vigilant and careful in giving opinions in social media, especially to controversial topics. Concerning politeness theory, posting in social media accounts could be a face-threatening act or face-saving act depending on the purpose of the imposition.

144 Consortia Academia Publishing (A partner of Network of Professional Researchers and Educators) 
According to one of the participants, "Politeness strategies lighten the emotional intensity created by confrontations of highly sensitive topics.". Just like the priest whose topic was about religion, his use of positive politeness, negative politeness, bald on-record, and off-record politeness lightened the intense feelings resonated from the viewers' anticipation of the outcome of his thinking knowing that he was priest. As Brown and Levinson (1987) asserted, when sensitive topics are put in question, the more one should elaborately use politeness strategies. Similarly, in the study, the priest succeeded by flawlessly and strategically using the four politeness strategies.

Another research participant remarked, "It shows the proper way to react on things around especially in showing respect to people around us." Just like the study of Dharmayanti, Sukarini, and Savitri (2018), Ellen DeGeneres's televised interview with Barack Obama, both the host and guest respected each other's image by not being rude and too imposing with their utterances. The interlocutors have showed deference and mutual respect because they understood that both were respected personalities in politics and media. Moreover, politeness strategies “....may cover up or protect the person you are giving reaction.”. This is true especially in using compliments and praise to give positive value to the hearer's face (Al-Azzawi, 2011), employing in-group identity marker to realize someone's sense of belongingness in the conversation (Jiang, 2010), showing sympathy and understanding of one's situation (Monsefi \& Hadidi, 2015), and establishing common ground to arrive at an understanding (Dowlatabadi, Mehri, \& Tajabadi, 2014). In these ways, the hearer would not feel aloof, neglected, and severely criticized. However, some strategies could likely attack hearer's face instead of protecting it. These involve sarcastic utterances (Barbe, 1995, as cited by Prokofiev, 2017) and ambiguous facial expressions (Hassin, Aviezer, \& Bentin, 2013). In these strategies, hearers would tend to doubt the clarity of the given imposition.

Thirdly, the research participants have acknowledged the importance of each politeness strategy in giving reactions. By examining their characteristics and witnessing how they were used in reaction vlogs, they were trained to evaluate issues and responses. They learned how each vlogger voices out their reactions and gained insights on how to react to topic if they would be put in the same situation as the vloggers. If given a chance to have their own reaction vlog, the participants realized the importance of each politeness strategy. One said about the balanced use between positive and negative politeness, "We can't just stay with what is good as is highlighted by the positive politeness. We also need to unravel mistakes and impose against it politely." In this statement, the participants highlighted the significance of satisfying both the positive and negative face of the hearers when giving reactions. Similarly, in the study conducted by Handoko (2014), the speaker Tony Abbot had used teasing to convince people that he cared for them. With this, he used positive and negative politeness.

When topics are complicated, another participant imparted, "Though to him it is fairly reasonable to use bare FTAs, I would probably use more redresses and would even do away with bald on record as it would be too imposing for a non-expert. I would be genuine with my positive politeness just as what medical procedures deserve.". With this, it was emphasized that positive politeness is appropriate, especially when a speaker is not an expert in a specific field. In this circumstance, positive politeness through giving praise and compliments could be used (Al-Azzawi, 2011; Brown \& Levinson, 1987).

To controversial topics, one participant shared, “I felt like I will use negative politeness because I don't want to offend the viewers so I will try to restrict myself in giving direct opinion about the video. I will use off-record politeness, I will use metaphors in giving reactions.". In these lines, one preferred to use negative and off-record politeness strategies to mitigate the potential offense to the hearer's face. According to Brown and Levinson (1987), both negative and off-record politeness use redressive utterances to satisfy the hearer's negative face or freedom of action. However, for the sake of ranking, off-record politeness can meet negative face more than what negative politeness can afford. Thus, in connection to the findings of this study, it could be deduced that in wanting not to offend the hearers, most people would prefer to use more redressive utterances.

In general, to make use of all strategies, another participant asserted, "One must maintain a good balance 
between positive and negative politeness, with occasions of bald on record in case of violation on widely accepted do's and don'ts, with an exception to controversial topics which do's and don'ts are still being debated. Off record is also useful for points that will lead the hearer to something without directly planting it in his/her head.". It could be inferred that Brown and Levinson's politeness strategies are all important in a conversation, and each strategy's appropriateness and effectiveness depend on the given context (Young, 2019) and the speaker's motives (Kim, 2017). More importantly, it was said that "These politeness strategies used in YouTube reactions vlogs gives us the freedom to evaluate the vlogger's way of speaking, his or her facial reactions, as well as the content itself.". Thus, with one's knowledge about politeness strategies, one can create impressions and judgments to the speaker and the topic of concern. Therefore, this encompasses what they termed as social competence (Stalnaker, 1972), pragmatic competence (Hedayat \& Kazemi, 2018), and interactional competence (Young, 2019).

Fourth, vlogging as a new form of self-expression has gained the interest of many people nowadays. Reaction vlog, with its investigative and critical characteristics, has led the participants to learn to appreciate vlogs. Especially in this study, where the reactors/vloggers were professional in various fields, the participants admired their bravery and honesty in giving their criticism and appreciation, sharing their personal experiences, and admitting their limitation in terms of knowledge to the viewers. It is stressed that as long as people are interested in watching other people, vlogs will always be popular (Mironova, 2016). One participant mentioned, "I like watching vlogs because they tell us about ourselves as well as represent a new form of self-expression, rooted in our today's communication environment.". It could not be denied that vlogs and vlogging have captivated people's interest especially now with the availability of gadgets and technology.

In this study, the participants enumerated the advantages of reaction vlogs concerning politeness strategies. To start with, one participant stated, "Hearing the experts; it may give you knowledge on things which are true on their field and maybe exaggerations on the videos they are giving reaction.". This was especially true when reactors used bald on-record politeness strategies to confirm the truthfulness of the content they were reacting. According to Brown and Levinson (1987), when one used direct utterance, the danger of being misunderstood is avoided. Equally, in using maximum efficiency as a bald on-record strategy, one emphasized the importance of something (Putri, 2013). With these, the hearers or viewers could learn and validate their knowledge. In addition, the participants asserted, "The politeness in this vlog influenced my sense of sympathy and understanding of the person in question.". As they immersed themselves on the convention of reaction vlogs, they saw how rich its context was not just in terms of content but also in the presence of politeness strategies. By cultivating their sense of sympathy and understanding, they were able to experience one of the sub-strategies of positive politeness that is oriented to satisfying the hearer's positive face (Brown \& Levinson, 1987; Monsefi \& Hadidi, 2015).

Furthermore, the participants appreciated the vloggers' ways of presenting their reactions. One participant observed, "I like how he wrapped criticism and the irrelevance of the iron-man technology by redirecting the audience into what he knows and what he does not as an engineer.". This pertained to the use of pessimism to lessen the dislike or displeasure of the hearers to the speaker's utterance (Rohali, 2019; Brown \& Levinson, 1987). Similarly, the vlogger (engineer) used pessimism to express his disagreement by saying he was not sure about the full capacity of technology. By thinking less or humbling himself rather than attacking the weak spots and loopholes of the content, the participants thought highly of his reaction vlog. Moreover, showing appreciation to the technique of the doctor, one said, "Not only did he provide medical assessment apparent to the episode of The Good Doctor but he kind of debunk some assumptions and well to being politely critical as far as his experience goes. This made his reaction vlogs worth to watch.”. The doctor's usage of positive politeness made him trustworthy, credible, and passionate about his profession. Through positive politeness, the doctor valued the hearers' faces by agreeing and deepening the relevance of the procedures presented in the content (Brown \& Levinson, 1987).

Fifth, the participants came to the consensus that politeness strategies could help in controlling and 
managing reactions. Usually in giving reactions in vlogs, viewers/audience not only listen to the words uttered but also examine the non-verbal cues of the speakers. In this situation, if one will rely only on the facial expressions and tone of the vloggers, there could be a misinterpretation of one's perception of the vloggers' personality and attitude toward the topic. With this, politeness strategies could be used to repair the potentially negative connotation of facial reactions and create a balance between verbal and facial reactions. As one of the participants' realization, one said, "The advantages of using politeness strategies in reaction vlogs in different context are freedom of mixing politeness strategies in a single setting and an effort to prevent or repair damages caused by the facial reactions by the speaker.”. As informed by Hassin, Aviezer, and Bentin (2013), facial expressions are inherently ambiguous, so it is hard to read and put a correct interpretation on them. Thus, one should not rely on the facial reactions only but must also consider the textual cues.

In addition, with politeness strategies, "One can actually remodify the conversation to less threatening.". As pointed by Brown and Levinson (1987), politeness strategies are used when one cannot afford to comment bluntly on topic that could potentially offend hearers in the conversation. As a result, the speaker would resort to polite utterances to make hearers comfortable in the communication process. With this, a less threatening conversation is more likely to be successful since interlocutors are free and comfortable to communicate. However, as mentioned by Bonnefon, Feeney, and De Neys (2011), the higher the degree of politeness strategies used, the higher the risk of confusion incurred to the hearers. Thus, they also encouraged people to be less polite in high-stakes situation and make a polite statement easier to interpret. With this, now, successful communication with an embedded application of politeness would depend on people's pragmatic or interactional competence.

Furthermore, based on the participants' sharing, "Politeness strategies also act as filters in expressing opinions in a way that is most acceptable or tolerable to the hearer.". In this statement, it is viewed that politeness is relative and varied depending on one's acceptable social norms. As enumerated by Brown (2015), one of the reasons for people's polite behavior is one's culture of acceptable polite standards. Sometimes, one's utterance could be considered polite to one culture but impolite to others. With this, it is vital to be sensitive and knowledgeable on one another's culture to maximize the use and benefits of politeness strategies.

Moreover, aside from the acceptable social norms, the use of politeness strategies also depends on the content and one's capability to give reactions. This is evident in the participant's statement, "Its usage depends on the situation or video you are reacting on and level of understanding in a certain topic.". This account pertains to the speaker's power to convey imposition. According to Culpeper (1996), impositions could be easily conveyed when the speaker is more potent than the hearer. In this study, the participants viewed the vloggers as powerful because they were certified professionals in specific field, so they have the authority to make judgments and reactions. On the other hand, the participants viewed themselves as less potent because they were non-expert on the field. Therefore, it could be deduced that experts may use lesser redressive utterances than non-experts.

Lastly, the participants asserted that there should be politeness strategies to limit the words or reactions of the vloggers. For example, if positive politeness is used, the nature of criticism is to give appreciation and approval; in negative politeness, respect, restraint, and formality are emphasized; in using bald on-record politeness, the speaker is oriented to being corrective and direct to the point; and in off-record politeness, criticism is non-imposing to the fact that hearers are free to give interpretation (Brown \& Levinson, 1987). Truly, politeness strategies act as guides that tell speakers the scope of criticism they should provide.

Sixth, when faced with an imposition, people have varying ways in responding. With the knowledge of politeness strategies, one could be developed to be a critical and analytical thinker. Being critical and analytical thinkers stem from being selective in the appropriate politeness strategies to use, firm in defending their claim, and well-informed of the consequence of an imposition. Thus, the quality and appropriateness of response must be carefully thought to avoid coercion.

In fact, the participants suggested various response when using politeness strategies. For instance, when 
giving advice, it is vital to put confidence and conviction on the utterances through the aid of bald on-record politeness. However, utterances should not be exaggerated and repeated several times to emphasize their importance because the tone and pitch of voice are also employed that could potentially affect the hearer's interpretation of the intended meaning. Thus, being confident, precise, and firm in the utterance could help the speaker avoid the danger of being misunderstood and seen as manipulator (Brown \& Levinson, 1987). Moreover, as a reasonable reactor, it is wise to investigate and confirm first the totality of the situation before commenting. In this way, the speaker could allot time in selecting the effective politeness strategy to employ. It is also essential to be sensitive and careful with the choice of words. However, if being blunt and direct is needed, then it must be so. By doing these, the aspects of social context (Young, 2019), accepted norms (Brown, 2015), one's ability or power (Culpeper, 1996), motives (Kim, 2017), and choice of content/topic are considered.

When reacting, being open-minded to the validity of a particular claim is regarded as polite. However, one must not be carefree in tolerating a debatable and untrue stance. This was earnestly applied by the priest in his reaction vlog when he first listened to Ariana's claim that God is a woman before correcting the claim in the later part of the vlog. In this circumstance, the positive politeness sub-strategies such as giving sympathy (Monsefi \& Hadidi, 2015) and avoidance of disagreement (Brown \& Levinson, 1987) were employed. Remarkably, one of the research participants asserted that he would want to avoid the topic in a circumstance where face-satisfying acts were not attainable. This act of avoidance adheres to the fifth politeness strategy proposed by Brown and Levinson (1987) but was not given too much emphasis. The fifth strategy is called don't do FTAs. In this circumstance, the speaker does not perform a face-threatening act that could damage the hearers' faces.

Lastly, since all participants were educators, they considered how reaction vlogs and politeness strategies could help aid in teaching-learning process. The participants expressed that politeness in reaction vlogs could contribute to teaching the concept of politeness strategies in pragmatics, the values of polite manner, and other relevant skills that learners could use. Equally, if used, the teachers will be held responsible for determining the appropriateness of the chosen reaction vlogs to be used in the classroom.

One participant shared that reaction vlogs are good springboard in teaching politeness theory and pragmatics. This is evident on the discussion above showing the elements of politeness depicted in reaction vlogs. In addition, politeness in reaction vlogs could be used in teaching communication in context with the integration of good values. As pointed by Frobenius (2014), vlogging is an act of recording one's experiences, opinions, and thoughts and sharing them on social media. Thus, vlogs contain authentic utterances of people with different background and varied communication environment which could help viewers learn about a language.

Also, politeness strategies in reaction vlogs serve as an illustration where student could model expressing their opinions and ideas. In the study conducted by Combe and Codreanu (2016), vlogging is an avenue where learners can practice their speaking skills, digital literacy skills, multilingual peer learning skills, opinion conflict solving skills, and intercultural skills informally. For instance, some students indulge in civic engagement by expressing their opinions about bullying (Caron, 2017). Thus, concerning the corpora of this study, learners could model a reaction vlog for them to express their responses on a given topic. In this way, students' higher-order thinking skills could also be developed. However, Werner (2012) stressed that involving learners in vlogging comes not just with benefits but also risks. With the judgmental eyes and ears in social media, learners' faces could be damaged. Thus, learners must learn first the convention of vlogging and its consequences before creating their own vlog content. Furthermore, in several studies, there were proof that students can learn about a language. In vlogging, vloggers apply opening and closing strategies closely related to face-to-face communication (De Boeck, 2015), hedging through modal auxiliaries and discourse markers (Nabilah, 2019), and usage of various language features (Lunaeldira, 2018). Through being exposed to these, students could attain language learning that is not just taught in the classroom.

In Indonesia, students have developed their listening skills, pronunciation, and vocabulary using vlogs through pausing in-between videos, using a dictionary, and avoiding subtitles (Safitri \& Khoiriyah, 2017). Just 
like how students manage to learn, teachers could also learn strategies for approaching sensitive themes by watching reaction vlogs. Aside from knowing the concepts of a particular topic, teachers could also get strategies on how to deliver sensitive topics in class through modeling the vloggers. However, teachers must be careful in choosing the reaction vlog to model their teaching. Justifiably, the participants also shared that since students are already exposed to social media, they might as well learn from it. According to Gallardo (2014), Millennials, although dubbed as digital natives, are knowledgeable in using mobile phones and other technology for social communication and personal interactions, but not expert in using them in educational purposes. With this, teachers or adults play a significant role in guiding learners to maximize the learning they could get from social media.

Overall, the participants have cited how politeness strategies in YouTube reactions vlogs influenced them and the viewers. Throughout this study, they realized that using politeness strategies in reaction vlogs makes one a good conversant and critical and analytical thinker since one will know what politeness strategies to employ, and what to say and how to voice out reactions. Also, its usage fosters giving respect and protecting image of the individuals who exerted effort in developing the content, the viewers who watched and listened to vlogs, and the reactors or vloggers who voiced out their judgment and opinions. Furthermore, knowing the role of each politeness strategy in conversation helps train one how to evaluate issues and reactions and help control and manage reactions. Finally, as reaction vlogs offer authentic use of language and politeness strategies serve as a guide to tolerable conduct, the participants learn to appreciate vlogs and enumerate ways on how it could be used to aid in teaching-learning process.

\subsection{Implications in Language Teaching}

The findings of the analyses in the politeness strategies could help in teaching communication in context as students could learn to express their opinions and ideas with the use of politeness strategies. Correspondingly, by introducing Brown and Levinson's politeness theory in the classroom, students could learn to classify and identify the politeness strategies used in the presented reaction vlogs and to their reactions. In doing so, reaction vlogs, as an investigative genre of vlog, could help teach students analytical and critical thinking skills with the integration of exemplary values or politeness. Moreover, the utilization of reaction vlogs by educators would help support multimodal learning as advocated by the educational institution. Reaction vlog, a digital multimodal text that incorporates linguistic, aural, visual, gestural, and spatial modes, could address the diversity of learners in the classroom. By letting learners model their reactions from a reaction vlog, they could develop their viewing comprehension as one of the macro-skills in language learning.

Similarly, by letting learners create their reaction vlogs on subject lessons, they could incorporate careful verbal and facial reactions to advocate politeness and language fluency. Reaction vlogging, if integrated as one of the learners' performance tasks, could be a novel undertaking in education. However, by considering the possible risks of expressing opinions on others, they may or may not post their reaction videos on public sites. Furthermore, the educational content of reaction vlogs could not only help teach English subjects and Values Education. Their content could support in teaching other subject areas such as Science, Mathematics, TLE (Technology and Livelihood Education), MAPEH (Music, Arts, Physical Education, Health), History, Philosophy, and the like. For instance, in this study, the doctor's reaction to a medical drama could provide valuable information in teaching Science and Health; the engineer's reaction to technology in the Iron Man movie and marines' reaction to the online game could aid in teaching the concepts of Science and Technology, Engineering, and Arts; the priest's reaction to the controversial song could spark meaningful discussions in Philosophy and History; and the chefs' reaction to cooking movie scenes could support TLE related concepts. Thus, reaction vlogs, as very rich educational sources, could serve as supplementary materials to support teaching and learning. However, if used, teachers must be cautious in choosing the content and topics.

Equally important, the results of this study could serve as basis in analyzing politeness strategies in digital platforms in the context of spoken media since most product studies are focused on written forms. The presence 
of authentic utterances in vlogs makes politeness unrehearsed and irreversible. Thus, other learning institution could use the classifications and analyses made on each type of politeness strategy as a reference in conducting their research. As a person who does prefer to listen more than to talk much, I usually am thrilled with listening to people voicing out their opinions that are paired with information and evidence. It does not just make you learn about facts; it also makes you understand how engaging other people's experiences are. With that, you will be drawn to listen, get motivation, and improve yourself day by day.

Concerning this study, listening and watching different people react to certain content makes you ponder how people become who they are by what they knew and what they believe. Sometimes, people tend to respond without knowing the whole story, some would respond after considering both sides, and some would respond without us even knowing that they are already giving reactions. The expressions of people's thoughts are genuinely fascinating. Equally fascinating is how the hearers take other people's reactions for themselves. Some hearers took opinions seriously and critically. Some seemed untroubled and unbothered. In ways that I cannot objectively explain how a single statement affects people differently, I choose to listen and attempt to understand.

When I stumbled on my research topic, reaction vlogs, I did not realize how important this kind of video content is in people's lives. Most of us are usually devoted to laughing, being amazed, being entertained, being looked at, being adored. We unknowingly forget to nourish our rational selves, us as thinking beings. Maybe, this could be the reason why in our country, most of the hateful comments and baseless claims posted against our government came from people who did not even bother to check the history of why and how things operate. Some, especially the youth, are participating in debates about social issues yet not at all acting as rational beings but only clinging to what is trending in social media.

As I engulfed myself in analyzing the implication and relevance of my study in society, I realized that this is not just about proving a theory (politeness strategies in particular). This is about sending a message to everyone to guard our mouths and nurture our thoughts at all costs. By looking at how reaction vloggers subjected in the study expressed their opinions, I learned that their authority to speak was established by the education they attained and the experiences they confronted in their respective fields. By having these two crucial aspects education and experience - one could sound believable and be listened to by the people. Further, it is essential to note that it is not all the time that we get to meet experts such as doctors, engineers, chefs, priests, and soldiers personally. Through their initiative to share their knowledge and experience online, we get to know their world slowly. Learning from them, made possible by reaction vlogs, is something we should be thankful for. It is like being freely educated by lots of experts from varying fields all over the world.

With my profession as teacher, I realized that the content in reaction vlogs made by experts is very helpful in education. Not only in validating the concepts written in books, but reaction vlogs could also take both learners and teachers to the lived experiences of the vloggers. Being able to connect with their experiences, although virtually and not personally engaged, could make the virtual encounter impactful. In terms of looking at reaction vlogging as a form of performance task among learners, I am confident that learners could do it, and teachers could facilitate it. As I recall, the birth of this study started when I overheard my Grade 10 students talking about their favorite vloggers and aspiration to become one. Seeing them engaged and fascinated by the vlogs and vlogging, I think it is about time to let them experience it inside the classroom.

Of relating to Brown and Levinson's theory of politeness, positive politeness is acceptable when the reactors are non-experts in a specific field because technical procedures and concepts deserve appreciation and compliments. Secondly, bald on-record politeness used by experts is suitable in giving immediate feedback and corrections since they are considered the font of knowledge and experience in their field of expertise. Next, off-record politeness is fitting in allowing viewers to think on their own and be responsible for their thinking. Lastly, negative politeness is equally needed to pay respect and deference to the content creators' efforts and feelings. With these guiding principles, I say that politeness strategies could not only be used by experts but also 
Analysis of politeness strategies in Youtube reaction vlogs

by ordinary people. Politeness, in general, is not merely satisfying the hearer's self-image but also protecting the speaker's face which makes the usage of politeness strategies beneficial for both interlocutors.

More so, there is a need to use politeness strategies in communication. It sets the limitation on the choice of words to use, and the level of emotional intensity embedded to every utterance. Being sensitive with other's feelings caused by our utterances is the first and foremost task a speaker must take responsibility for. This is not just for the sake of protecting our image and maintaining other people' opinions about us, this is also about caring for what others may feel by what we say and act. By doing this, communication will indeed be sustained, and harmonious rapport between communicators will be achieved. With much gratitude and respect, I commend how the research participants showed their prowess and expertise in analyzing the politeness strategies used in the reaction vlogs. The participants benevolently lend their expertise to shed light on this research's objective. Like the vloggers who are experts in giving their reactions to various topics, the research participants are also experts in this analysis field.

In addition, exploring corpus analysis was new to me. This research journey has been memorable since I got oriented and exposed to its convention. Being able to experience collecting data source such as reaction vlogs taught me not just knowledge on varied concepts in different fields but also the benefit of using corpora in language research. Finally, accomplishing this study in the middle of pandemic is a fulfilling milestone in my life as a qualitative researcher. There were ups and downs and feats and fiascos in doing this research. Fortunately, by grace through faith and with the company of my constant motivators, I was able to thrive and fulfill the research objectives.

\section{References}

Adel, S., Davoudi, M., \& Ramezanzadeh, A. (2016). A qualitative study of politeness strategies used by Iranian EFL learners in a class blog. Iranian Journal of Language Teaching Research, 4(1), 47-62. https://files.eric.ed.gov/fulltext/EJ1127416.pdf

Akaranga, S.I., \& Makau, B. K. (2016). Ethical considerations and their application to research: A case of the University of Nairobi. Journal of Educational Policy and Entrepreneurial Research, 3(12), 1-9. https://profiles.uonbi.ac.ke/kuria_paul/files/429-825-2-pb.pdf

Akram, W., \& Kumar, R. (2017). A study on positive and negative effects of social media on society. International Journal of Computer Sciences and Engineering, 5(10), 351-354. https://doi.org/10.26438/ijcse/v5i10.351354

Al-Azzawi, J. N. (2011). Compliments and positive politeness strategies. Iraq Academic Scientific Journal, 1-16. https://www.iasj.net/iasj/download/b522faa53506dbee

Al-Duleimi, H., Rashid, S., \& Abdullah, A. N. (2016). A critical review of prominent theories of politeness. Australian International Academic Centre, 7(6), 262-270. https://doi.org/doi.org/10.7575/aiac.alls.v.7n.6p.262

Arifin, S.R. (2018). Ethical considerations in qualitative study. International Journal of Care Scholars, 1(2), 30-33. https://journals.iium.edu.my/ijcs/index.php/ijcs/article/view/82

Austin, J. (1965). How to do things with words: The William James lectures delivered in Harvard University in 1955. Oxford University Press. https://philpapers.org/rec/AUSHTD-2

Bailey, J. (2008). First steps in qualitative data analysis: Transcribing. Oxford Journals, 25, 127-131. https://doi.org/10.1093/fampra/cmn003

Baraceros, E. (2016). Practical Research 1. Rex Book Store

Barbe, K. (1995). Irony in Context. John Benjamins Publishing Company. https://doi.org/10.2307/415936

Bennett, G. (2010). Using corpora in the language learning classroom: Corpus linguistic for teachers. University of Michigan Press. http://www.press.umich.edu/titleDetailDesc.do?id=371534

Berryman, R., \& Kavka, M. (2018). Crying on YouTube: Vlogs, self-exposure and the productivity of negative affect. Convergence: The International Journal of Research into New Media Technologies, 24(1), 85-98. https://doi.org/10.1177/1354856517736981 
Alcosero, I. R., \& Gomez, D.

Biber, D., Conrad, S., \& Reppen, R. (1998). Corpus linguistics: Investigating language structure and use. Cambridge University Press. http://assets.cambridge.org/97805214/99576/excerpt/9780521499576_excerpt.pdf

Bonnefon, J. F., Feeney, A., \& De Neys, W. (2011). The risk of polite misunderstandings. Current Directions in Psychological Science, 20(5), 321-324. https://doi.org/10.1177/0963721411418472

British Association for Applied Linguistics. (2006). Recommendations on good practice in applied linguistics ( $2^{\text {nd }}$ ed). http://www.baal.org.uk/dox/goodpractice_full.pdf

Brown, P. \& Levinson, S. C. (1978). Universals in language usage: Politeness phenomena. In E.N. Goody (Ed.), Questions and politeness: Strategies in social interaction (pp. 56-311). Cambridge University Press. https://pure.mpg.de/pubman/faces/ViewItemOverviewPage.jsp?itemId=item_66660

Brown, P. \& Levinson, S. C. (1987). Studies in interactional sociolinguistics, 4. Politeness: Some universals in language usage. Cambridge University Press.https://www.academia.edu/26395652/Politeness_Some_universals_in_language_usage

Brown, P. (2015). Politeness and language ( $\left.2^{\text {nd }} \mathrm{ed}\right)$. The International Encyclopedia of the Social and Behavioural Sciences, 3, 326-330. https://doi.org/10.1016/B978-0-08-097086-8.53072-4

Bruckman, A. (2002). Ethical guidelines for research online. http://www.academia.edu/download/30821087/irb_ethics_online.pdf

BuzzFeedVideo. (2018, November 13). Real chefs review cooking movie scenes [Video]. YouTube. https://www.youtube.com/watch?v=BvhY0TyB28I\&t=6s

Caron, C. (2017). Speaking up about bullying on YouTube: Teenagers' vlogs as civic engagement. Canadian Journal of Communication, 42(4), 645-668. https://doi.org/10.22230/cjc.2017v42n4a3156

Chikwaya, T., \& Zhang, Y. (2018). Commerce \& friendship: A qualitative study of new value streams created by beauty vloggers through relationship building on social media. Linköping University Electronic Press, 1-93. http://www.diva-portal.org/smash/get/diva2:1219096/FULLTEXT01.pdf

Combe, C., \& Codreanu, T. (2016). Vlogging: A new channel for language learning and intercultural exchanges. In S. Papadima-Sophocleous, L. Bradley \& S. Thouësny (Eds.), CALL communities and culture - short papers from EUROCALL 2016 (pp. 119-124). Research-publishing.net https://doi.org/10.14705/rpnet.2016.eurocall2016.548

Coskun, A. (2016). Causes of the 'I can understand English but I can't speak' syndrome in Turkey. I-Manager's Journal on English Language Teaching, 6(3), 1-12.

Creswell, J. \& Miller, D. (2000). Theory into practice: Getting good qualitative data Determining validity in qualitative inquiry. The Ohio State University. https://doi.org/10.1207/s15430421tip3903_2

Creswell, J. (2008). Educational research: Planning, conducting, and evaluating quantitative and qualitative research (3rd ed.). Upper Saddle River, NJ: Pearson Education, Inc.

Creswell, J. (2013). Qualitative inquiry and research design: Choosing among the five traditions. Sage Publications.

Creswell. J. (2012). Educational research: Planning, conducting, and evaluating quantitative and qualitative research $\left(4^{\text {th }}\right.$ ed $)$. Pearson Education, Inc. https://www.scoop.it/topic/nzpvjgj/p/4098695963/2018/06/24/creswell2012-pdf

Culpeper, J. (1996). Towards an anatomy of impoliteness. Journal of Pragmatics, 25, 349-367. http://www.academia.edu/download/50298104/03782166_2895_2900014-320161114-19966-1ox5nbf.p df

Cutrone, P. (2011). Politeness and face theory: Implications for the backchannel style of Japanese L1/L2 speakers. University of Reading, 3, 51-57.

Dash, N. S. (2010). Corpus linguistics: An introduction. Encyclopedia of Life Support Systems. http://www.eolss.net/sample-chapters/c04/e6-91-17.pdf

De Boeck, J. (2015). Opening and closing strategies in YouTube vlogs: How monologues encourage conversation [MA Thesis]. Universiteit Antwerpen. https://www.scriptiebank.be/sites/default/files/JessicaDeBoeck_OpeningAndClosingStrategiesInYouTu beVlogs.pdf

152 Consortia Academia Publishing (A partner of Network of Professional Researchers and Educators) 
Analysis of politeness strategies in Youtube reaction vlogs

Dharmayanti, N., Sukarini, N., \& Savitri, P. (2018). Politeness strategies used in Ellen DeGeneres’s TV talk show with Barack Obama as the guest star. Jurnal Humanis, 22(1), 142-146. https://doi.org/10.24843/JH.2018.v22.i01.p21

Doctor Mike. (2018, April 15). Real doctor reacts to The Good Doctor: Medical drama review [Video]. YouTube. https://www.youtube.com/watch?v=Ya trlAWIXA\&t=38s

Dowlatabadi, H., Mehri, E., \& Tajabadi, A. (2014). Politeness strategies in conversation exchange: The case of Council for Dispute Settlement in Iran. Procedia-Social and Behavioral Sciences, 98, 411-419. https://doi.org/10.1016/j.sbspro.2014.03.434

Eshghinejad, S., \& Moini, M. R. (2016). Politeness strategies used in text messaging: Pragmatic competence in an asymmetrical power relation of teacher-student. $S A G E, 1-13$. https://doi.org/10.1177/2158244016632288

Febtrina, R. (2019). A pragmatic analysis of politeness strategies and cooperation principles in Beauty and the Beast movie. IOSR Journal of Research \& Method in Education, 9(3), 6-11. https://doi.org/10.9790/1959-0903010611

Fraser, B. (1990). Perspectives on politeness. Journal of Pragmatics, 14, 219-236. https://doi.org/10.1016/0378-2166(90)90081-N

Gallardo, E. (2014). An investigation of the social and academic uses of digital technology by university students. Universitat Rovira I Virgili. https://www.tdx.cat/bitstream/handle/10803/277423/Thesis_EG_final.pdf?sequence=1\&isAllowed=y

Gamology. (2020, July 26). Female marines react to Omaha Beach from Call of Duty WWII: Experts react [Video]. YouTube. https://www.youtube.com/watch?v=0703kdrrFfT8\&t=259s

Garcia, F. (2014). Impoliteness, pseudo-politeness, strategic politeness? On the nature of communicative behavior in electoral debates. Circle of Linguistics Applied to Communication, 58, 60-89. http://doi.org/10.5209/rev_CLAC.2014.v58.45470

Gibbs, R.W. Jr. (2000). Irony in talk among friends. Metaphor and Symbol, 15(1-2), 15-27. https://doi.org/10.1207/S15327868MS151\&2_2

Greenbank, P. (2003). The role of values in educational research: The case for reflexivity. British Educational Research Journal, 29(6), 791-801. https://doi.org/10.1080/0141192032000137303

Greysen, S. R., Kind, T., \& Chretien, K. C. (2010). Online professionalism and the mirror of social media. Journal of General Internal Medicine, 25(11), 1227-1229. https://doi.org/10.1007/s11606-010-1447-1

Gunawan, J. (2015). Ensuring trustworthiness in qualitative research. Belitung Mursing Journal, 1(1), 10-11. https://doi.org/10.33546/bnj.4

Handoko, P. Z. (2014). Politeness strategies in Tony Abbot speech concerning Australia-Indonesia tapping issue. Jurnal Ilmiah Mahasiswa Fib, 6(2), http://jimbastrafib.studentjournal.ub.ac.id/index.php/jimbastrafib/article/view/598

Hassin, R. R., Aviezer, H., \& Bentin, S. (2013). Inherently ambiguous: Facial expressions of emotions, in context. Emotion Review, 5(1), 60-65. https://doi.org/0.1177/1754073912451331

Haythornthwaite, C. (2011). Social networks and internet connectivity effects. Information, Community \& Society, 8(2), 125-147. https://doi.org/10.1080/13691180500146185

Hedayat, K., \& Kazemi, F. (2018). The role of politeness in the employee-client speech interactions. Theory and Practice in Language Studies, 8(1), 100-104. http://doi.org/10.17507/tpls.0801.13

Johansson, M. (2017). YouTube. In C.R. Hoffmann, \& W. Bublitz (Eds.), Pragmatics of Social Media (pp. 173-200). De Gruyter Mouton. http://doi.org/0.1515/9783110431070-007

Jiang, X. (2010). A case study of teacher's politeness in EFL class. Journal of Language Teaching and Research, 1(5), 651-655. https://doi.org/10.4304/JLTR.1.5.651-655

Jolly. (2018, August 03). British priest reacts to “God is a Woman” by Ariana Grande [Video]. YouTube. https://www.youtube.com/watch? $\mathrm{v}=\mathrm{dXnBw6THJfU \& \textrm {t } = 4 5 9 \mathrm { s }}$

Kamlasi, I. (2017). The positive politeness in conversations performed by the students of English study program of Timor University. Journal of English Language, Literature, and Teaching, 1(2), 68-81. https://doi.org/10.31002/metathesis.v1i2.467 
Alcosero, I. R., \& Gomez, D.

Katz, E., \& Blumler, J.G. (1974). The uses of mass communications: Current perspectives on gratifications research. Sage Publications, Inc. https://espace.library.uq.edu.au/view/UQ:730080

Khalid, K., \& Siddiqui, D. A. (2019). Branding with vlogs, factor affecting their success. Macrothink Institute Business and Management Horizons, 7(1), 49-77. https://doi.org/10.5296/bmh.v7i1.14402

Kim, M. S. (2017). Culture-based conversational constraints theory. The International Encyclopedia of Intercultural Communication. https://doi.org/10.1002/9781118783665.ieicc0102

Krueger, R. (2002). Designing and conducting focus group interviews. Semantic Scholar. https://www.eiu.edu/ihec/Krueger-FocusGroupInterviews.pdf

Leech, G (2014). The Pragmatics of Politeness. Oxford University Press. https://doi.org/10.1093/acprof:oso/9780195341386.001.0001

Leech, G. (1980). Explorations in semantics and pragmatics. John Benjamins Publishing. https://doi.org/10.1075/pb.i.5

Leech, G. (1983). Principles of pragmatics $\left(1^{\text {st }} \mathrm{ed}\right)$. Routledge. https://www.routledge.com/Principles-ofPragmatics/Leech/p/book/9780582551107

Leung, L., \& Wei, R. (2000). More than just talk on the move: Uses and gratifications of the cellular phone. Journalism \& Mass Communication Quarterly. https://doi.org/10.1177/107769900007700206

Liao, M. (2019). Politeness in the courtroom discourse. Forensic Research \& Criminology International Journal. 7(2), 45-61. http://doi.org/ 10.15406/frcij.2019.07.00264

Lincoln, Y. S., \& Guba, E. G. (1985). Naturalistic inquiry. Sage Publications, Inc. https://ethnographyworkshop.files.wordpress.com/2014/11/lincoln-guba-1985-establishing-trustworthin ess-naturalistic-inquiry.pdf

Lindgren, S. (2011). Collective problem-solving and informal learning in networked publics: Reading vlogging networks on YouTube as knowledge communities. In E. Dunkels, G. Frånberg \& C. Hällgren (Eds.), Interactive media use and youth: Learning, knowledge exchange and behavior (pp. 50-64). IGI Global. https://doi.org/10.4018/978-1-60960-206-2.ch004

Lunaeldira, H.G. (2018). Women's language features used by beauty vloggers in describing summer make-up tutorials. USD Repository. https://repository.usd.ac.id/31443/2/141214073_full.pdf

Maros, M., \& Rosli, L. (2017). Politeness strategies in Twitter updates of female English language studies Malaysian undergraduates. The Southeast Asian Journal of English Language Studies, 23(1), 132-149. https://doi.org/10.17576/3L-2017-2301-10

Mason, M. (2010). Sample size and saturation in $\mathrm{PhD}$ studies using qualitative interviews. Forum: Qualitative Social Research,11 (3). https://doi.org/10.17169/fqs-11.3.1428

Merriam, S. B. (1998). Qualitative research and case study applications in education (2 ${ }^{\text {nd }}$ ed). Jossey-Bass Publishers. https://searchworks.stanford.edu/view/3511521

Miles, M. B., \& Huberman, A. M. (1994). Qualitative data analysis: An expanded sourcebook (2 ${ }^{\text {nd }}$ ed). Sage Publications, Inc. https://psycnet.apa.org/record/1995-97407-000

Mironova, E. (2016). Audience's behavior and attitude towards lifestyle video blogs on YouTube. Malmö University Electronic Publishing. https://muep.mau.se/handle/2043/21024

Mishler, E. (1990). Validation in inquiry-guided research: The role of exemplars in narrative studies. Harvard Educational Review, 60(4), 415-443. https://doi.org/10.17763/haer.60.4.n4405243p6635752

Monsefi, M., \& Hadidi, Y. (2015). Male and female EFL teachers' politeness strategies in oral discourse and their effects on the learning process and teacher-student interaction. International Journal on Studies in English Language and Literature, 3(2) 1-13. https://www.arcjournals.orgs

Mugenda, A. G. (2008). Social Science Research: Theory and Principles. Acts Press

Mujiono, M., \& Ula, A. L. (2020). Sociopragmatic Analysis of Politeness Strategy of the Main Character's Dialogues of Tinker Bell in Secret of the Wings Movie. Indonesian Journal of EFL and Linguistics, 5(2), 229-251. https://www.researchgate.net/publication/346702318

Mulyono, E. (2016). Politeness principle analysis in cartoon movie entitled Stand by me Doraemon. Premise Journal, 5(1), 9-23. https://doi.org/10.24127/pj.v5i1.413

Mulyono, H., Rizki, D., \& Suryoputro, G. (2019). Politeness Strategies in Teacher-Student WhatsApp

154 Consortia Academia Publishing (A partner of Network of Professional Researchers and Educators) 
Analysis of politeness strategies in Youtube reaction vlogs

Communication. Journal of Language Teaching and Learning in Thailand, 58, 295-318. https://files.eric.ed.gov/fulltext/EJ1226910.pdf

Nabilah, R. (2019). The use of language features between men and women on YouTube vlog. Universitas Islam Negeri. http://digilib.uinsby.ac.id/33858/

Neuendorf, K. A. (2019). Content analysis and thematic analysis. In P. Brough (Ed.), Research methods for applied psychologists: Design, analysis and reporting (pp. 211-223). Routledge https://academic.csuohio.edu/kneuendorf/vitae/NeuendorfCA_TA_19.pdf

Pishghadam, R., \& Navari, S. (2012). A study into politeness strategies and politeness markers in advertisements as persuasive tools. Mediterranean Journal of Social Sciences, 3(2), 161-171. https://doi.org/10.5901/mjss.2012.v3n2.161

Poluzhyn, M.M., \& Vrabel, T.T. (2005). Lectures and methods-Guides for seminars on the course for choice: Basic problems of speech act theory. [Seminar]. https://dspace.uzhnu.edu.ua/jspui/bitstream/lib/8878/1/Speech\%20Act\%20Theory.pdf

Prokofiev, G. (2017). Differentiation between irony and sarcasm in contemporary linguistic studies. Alfred Nobel University Journal of Philology, 1(13), 233-239. http://doi.org/10.32342/2523-4463-2017-0-13-233-239

Punch, K. F. (1998). Introduction to social research: Qualitative and quantitative approaches ( $3^{\text {rd }}$ ed). Sage Publications, Inc. https://uk.sagepub.com/en-gb/eur/introduction-to-social-research/book237782

Putri, L. (2013). Analysis of politeness strategies used in Oprah Winfrey's talk show with Ricky Martin as guest star. Humanis: Journal of Arts and Humanities. https://ojs.unud.ac.id/index.php/sastra/article/view/4429

Rahayuningsih, D., Saleh, M., \& Fitriati, S. W. (2020). The realization of politeness strategies in EFL teacher-students classroom interaction. English Education Journal, 10(1), 85-93. https://doi.org/10.15294/EEJ.V10I1.33822

Rea, F. (2015). Web 2.0: Which factors make a YouTube channel successful on the internet?. Luiss Thesis. http://tesi.luiss.it/16506/1/651311.pdf

Rohali, R. (2019). Politeness strategy of directive speech act by students-lecturers of French department FBS UNY. Atlantis Press, 301, 545-551. http://doi.org/10.2991/icla-18.2019.89

Rosanti, I., Wijayanto, A., \& Hikmat, M. H. (2017). Impoliteness in criticism in vlog. Electronic Thesis and Dissertations: Universitas Muhammadiyah Surakarta. http://eprints.ums.ac.id/id/eprint/52121

Sadighi, F., \& Dastpak, M. (2017). The sources of foreign language speaking anxiety of Iranian English language learners. International Journal of Education \& Literacy Studies. https://doi.org/10.7575/aiac.ijels.v.5n.4p.111

Safitri, N.S., \& Khoiriyah, I. (2017). Students' perceptions on the use of English blog (video blog) to enhance speaking skill. In ASEAN/Asian Academic Society International Conference Proceeding Series (pp. 240-247). http://aasic.org/proc/aasic/article/view/298

Sandelowski, M. (1993). Rigor or rigor mortis: The problem of rigor in qualitative research. Advances in Nursing Science. https://doi.org/10.1097/00012272-199312000-00002

Sari, Y.K. (2016). An analysis of politeness strategy in Barack Obama's victory speech. Universitas Islam Negeri. https://repository.uinjkt.ac.id/dspace/bitstream/123456789/34405/1/YANI\%20KURNIA\%20SARI-FAH .pdf

Searle, J. (1975). Indirect speech acts. BRILL Publishing. https://doi.org/10.1163/9789004368811_004

Sharma, G. (2017). Pros and cons of different sampling techniques. International Journal of Applied Research, 3(7), 749-752. https://www.allresearchjournal.com/archives/2017/vol3issue7/PartK/3-7-69-542.pdf

Stalnaker, R.C. (1972). Pragmatics. In D. Davinson \& G. Harman (Eds.), Semantics of natural language (pp. 380-397). Springer. https://doi.org/10.1007/978-94-010-2557-7_11

Sulistiyaningsih, E. F., Mujiyanto, J., \& Widhiyanto, W. (2021). The use of negative politeness strategies in casual conversation among the graduate program students. English Education Journal, 11(2), 228-236. https://journal.unnes.ac.id/sju/index.php/eej/search

Susanti, R., \& Rohmadi, M. (2018). Politeness principles and strategies in language used by President Joko Widodo to Indonesian citizens, through vlog \#JOKOWIMENJAWAB. In The 1st International Seminar on Language, Literature and Education (pp. 798-806). KnE Social Sciences. 
Alcosero, I. R., \& Gomez, D.

https://doi.org/10.18502/kss.v3i9.2744

The Gold Life. (2019, April 14). Real engineer reacts to technology in Iron Man: Video by Pary Chahal [Video]. YouTube. Thhps://www.youtube.com/watch?v=CzOHEY8Abha\&t=677s

US Department of Health and Human Services (1979). The Belmont Report: Ethical principles and guidelines for the protection of human subjects on research. https://www.researchgate.net/publication/298079704

Valimbo I.A., \& Hartati, E. (2019). Application to improve students speaking skill: A classroom action research. Konferensi Pendidikan Nasional. 91-97.

http://ejurnal.mercubuanayogya.ac.id/index.php/Prosiding_KoPeN/article/view/890

Warmbrodt, J. (2007). An exploratory study of the videoblogger's community. Missouri S\&T Library and Learning Resources. http://scholarmine.mst.edu/masters theses/4575

Werner, E. A. (2012). Rants, reactions, and other rhetorics: Genres of the YouTube vlog. ProQuest Ebook Central. https://doi.org/10.17615/nna9-qz22

Xavierine, J., \& Thayalan, X. (2017). Impoliteness strategies in the social media comments on the low Yat Plaza incident. University of Malaya Research Repository. http://studentsrepo.um.edu.my/8532/

Yanti, R. (2017). An analysis of off record strategies reflecting politeness implicature in "Oprah Winfrey Show”. Jurnal Arbitrer, 4(1), 52-57. https://doi.org/ 10.25077/ar.4.1.52-57.2017

Young, R. F. (2019). Interactional competence and L2 pragmatics. In N. Taguchi (Ed.), The Routledge handbook of second language acquisition and pragmatics (pp. 93-110). Routledge.

https://www.researchgate.net/publication/329427987 